\title{
Preparation of magnetic metal-organic frameworks with high binding capacity for removal of two fungicides from aqueous environments
}

\author{
Jiping Ma ${ }^{\mathrm{a}, *}$, Shuang $\mathrm{Li}^{\mathrm{a}}$, Gege $\mathrm{Wu}^{\mathrm{a}}$, Maryam Arabi ${ }^{\mathrm{b}}$, Feng Tan ${ }^{\mathrm{c}}$, Yafeng Guan ${ }^{\mathrm{d}}$, Jinhua $\mathrm{Li}^{\mathrm{b}}$, \\ Lingxin Chen ${ }^{\mathrm{b}, *}$ \\ ${ }^{a}$ School of Environmental \& Municipal Engineering, State-Local Joint Engineering Research Center of Urban Sewage Treatment and Resource Recovery, \\ Qingdao University of Technology, Qingdao 266033, China \\ b CAS Key Laboratory of Coastal Environmental Processes and Ecological Remediation, Shandong Key Laboratory of Coastal Environmental Processes, Research \\ Center for Coastal Environmental Engineering and Technology, Yantai Institute of Coastal Zone Research, Chinese Academy of Sciences, Yantai 264003, China \\ ${ }^{\mathrm{c}}$ Key Laboratory of Industrial Ecology and Environmental Engineering (MOE), School of Environmental Science and Technology, Dalian University of \\ Technology, Dalian 116024, China \\ ${ }^{\mathrm{d}}$ CAS Key Laboratory of Separation Sciences for Analytical Chemistry, Dalian Institute of Chemical Physics, Chinese Academy of Sciences, Dalian 116023, China
}

\section{A R T I C L E I N F O}

\section{Article history:}

Received 18 February 2020

Received in revised form 6 July 2020

Accepted 9 July 2020

Available online 15 July 2020

\section{Keywords:}

Fungicide

Metal-organic frameworks (MOFs)

Magnetic separation

Adsorptive removal

Water treatment

\begin{abstract}
A B S T R A C T
A novel kind of Zr-based magnetic metal-organic frameworks (MMOFs) was prepared by immobilization of UiO-66 onto $\mathrm{Fe}_{3} \mathrm{O}_{4} @ \mathrm{SiO}_{2}$ particles via an efficient one-pot solvothermal method. Subsequently, it was used for adsorptive removal of triclosan (TCS) and triclocarban (TCC) fungicides from aqueous environments by magnetic solid phase separation. Morphology and physical/chemical features of the MMOFs were fully characterized by XRD, SEM, TEM, FT-IR, and VSM etc., showing high specific surface area, appropriate functionality, and desirable magnetic property. Several main factors affecting the adsorption performances of TCS and TCC on the MMOFs were systematically investigated and optimized, such as $\mathrm{pH}$ value of water sample, amounts/types of adsorbent and salinity. Under the optimized conditions, short adsorption equilibrium time (only $25 \mathrm{~min}$ ) and outstanding saturated adsorption capacities (476.27 and $602.40 \mathrm{mg} \cdot \mathrm{g}^{-1}$ for TCS and TCC, respectively) were the remarkable superiorities of the MMOFs compared with that of most reported adsorbents. The MMOFs demonstrated excellent adsorption selectivity for TCS and TCC and anti-interference ability. Also, the reusability for at least 11 cycles was another major profit of the MMOFs that saved cost and prevented waste. Moreover, the MMOFs demonstrated satisfactory removal/purification ability for actual environmental water samples. These benefits propounded a promising outlook of employing the MMOFs for influential removal of pollutants with considerable reliability in the field of wastewater treatment.
\end{abstract}

(C) 2020 The Korean Society of Industrial and Engineering Chemistry. Published by Elsevier B.V. All rights reserved.

\section{Introduction}

Limitation of water consumable resource, development of industry and human activities near the water stressed areas could have a serious detrimental impact on the quality of the Earth's water. Owing to the rapid growth of human population, the consumption of pharmaceutical and personal care products (PPCPs) are inevitably increased in people's daily lives [1]. Among them, the active fungicides added in personal care products can enter and accumulate in the environment with the discharge of sewage, and pose a threat to the safety of aquatic organisms and drinking water sources. Hence, residual fungicides are a kind of

\footnotetext{
* Corresponding authors.

E-mail addresses: majiping2012@163.com (J. Ma), Ixchen@yic.ac.cn (L. Chen).
}

emerging pollutant agent, which has been widely concerned at present because of their poor degradability in natural environmental conditions [2-4]. Triclosan (TCS) and triclocarban (TCC) (Fig. S1) are the two most widely used and high-efficiency fungicides in PPCPs by inhibiting the synthesis of lipid organisms by acting on enzymes [5]. TCS is listed as a potential carcinogen because it can be metabolized to dioxins [6]. As well as, it can cause methemoglobinemia and even affect mammalian reproduction and survival. Studies have shown that TCS and its degradation products are highly toxic to organisms such as fish and algae at $\mu \mathrm{g}$ $\mathrm{L}^{-1}$ levels and can affect thyroid function in amphibians [7,8]. Besides, both TCS and TCC have genotoxicity and endocrine disrupting effects, which can cause liver and kidney damage, and have an impact on the immune system [9-11]. Due to its wide range of uses, TCS and TCC are often detected in groundwater, drinking water and wastewater [12]. The traditional process in 
wastewater treatment plants makes it difficult to completely remove TCS and TCC. Therefore, it is very important to establish methods for efficiently removing TCS and TCC from the water environments.

At present, some researchers have adopted biodegradation [1315], advanced oxidation [16-18] and adsorption [19-24] methods to remove TCS and TCC from water. Among them, the biodegradation method has lower processing cost and lower energy consumption. However, the undesirable treatment efficiency, too long removal time, generation of by-products, and easy variation with the environmental changes have significantly limited the practical application. Although advanced oxidation process has higher removal efficiency, easy control of reaction process and high stability, it still faces the main defects such as high energy consumption and producing toxic intermediates and by-products. The adsorption method is frequently used for water treatment, which has higher treatment performance and lower energy consumption, and is more preferable for large scale operating compared with the above-mentioned two techniques. Meanwhile, obviously, this method has its inherent shortcomings as well viz. low binding capacity, contamination caused by leakage of the adsorbents into the water, and difficulty for isolating the adsorbents, that seriously needs to be overcome [24]. Therefore, it is a vital task to design worthy adsorbents with large specific surface area, stable structure, good water dispersibility, rapid separation from water and recyclability for removal of TCS and TCC. At first glance, bio-based adsorbents seem to be a viable option and frequently utilized for pollution removal. However, they cannot be used in the same form that they are derived from nature and need pretreatment or activation that is often sophisticated and costly. Also, their adsorption characteristic and reusability are not good enough to overlook their mentioned shortcomings. Hence, synthetic adsorbents are more preferable owing to physical and chemical properties predictability and various preparation routes.

Metal-organic frameworks (MOFs) are a new class of functional materials, which are porous and comprised of the hybridization of metal centers and multifunctional organic ligands [25,26]. They benefit from advantages like large porosity and specific surface area, adjustable pore size, diverse structure, and functional groups, unsaturated metal sites, and good biocompatibility, leading to wide use in gas storage [27,28], drug carriers [29], sensors [30,31], catalysis [32,33] and pollutant adsorption [34-38]. Amongst the available MOFs, $\mathrm{Zr}$-based ones are attractive owing to their good chemical and thermal stability [39], especially good structural stability in aqueous media profitable over most MOFs. The strong $\mathrm{Zr}$ (IV)-O bonds from zirconium metal nodes and organic ligands endow Zr-MOFs with excellent stability in aqueous solution over a wide $\mathrm{pH}$ range [40]. UiO-66, a typical kind of Zr-MOFs, has excellent hydrophilicity and small cage diameter of $6 \AA$ [41]; so, it can easily disperse in aqueous media and trap organic pollutants. To the best of our knowledge, for the adsorption based removal process, most of the scientists have focused on adsorbents' performance and tried to achieve higher removal efficiency. However, leakage of adsorbents is a forgotten problem, and may be the contamination caused by these adsorbents is more than the pollutants. There are two ways to minimize environmental damage arising from adsorbents. First, utilizing eco-friendly adsorbents, and second, isolating the adsorbents from the environment after the adsorption process. To prove that one adsorbent is eco-friendly or not, a lot of testing and a long time are required. Even if the ecofriendly property of the adsorbent is demonstrated, usage more than threshold limit is not rational. On the other hand, while ecofriendly absorbents are released into the environment, their nature may be altered by environmental variables such as sunlight, temperature changes and the products resulting from their decomposition can be highly toxic. Therefore, although some previous works reported that MOFs are eco-friendly materials $[42,43]$, it is safer to separate them from the water after adsorption.

By packing MOF into the column or anchoring to the membrane, the problems such as channeling column and blocking membrane/ column can occur. In addition, during the packing process, some of the adsorbents are lost. For conquering these shortcomings, magnetic materials are introduced to provide qualified adsorbents that could easily be separated from aqueous media by simply using an external magnetic field without centrifugation or filtration. The magnetic MOFs (MMOFs) composite has the advantages of both MOFs and magnetic separation technology and is more conducive to the application for removal of pollutants in water. In this regard, some studies have focused on the preparation of the MMOFs for removing environmental pollutants in water [44,45]. Various types of interactions such as hydrogen bonding, acid-base, coordination, electrostatic, hydrophobic and $\pi-\pi$, or their dual/multiple combination can participate for selective adsorption of pollutants by MOFs. Exploring the adsorption mechanism is essential, because without deep knowledge of adsorbate-adsorbent interactions, it is undeniably impossible to design versatile MOFs with the aim of pollutants adsorption. For example, Shi et al. designed and synthesized a recyclable $\mathrm{Cu}-\mathrm{MOFs} / \mathrm{Fe}_{3} \mathrm{O}_{4}$ composite to physically adsorb organic dyes through pores [46]. Huang et al. used Bi-I functionalized magnetic HKUST-1 MOF composite to selectively remove $\mathrm{Hg}^{2+}$ from water by electrostatic interaction [47]. In our group, magnetic copper-based MOFs were prepared for effective removal of two fluoroquinolone antibiotics from aqueous solutions through electrostatic and $\pi-\pi$ interactions [48]. Zhang et al. utilized amino-modified magnetic UiO-66 viz. UiO-66- $\mathrm{NH}_{2}$ MMOFs to remove salicylic acid and acetylsalicylic acid by electrostatic interaction [49]. As can be seen, due to the different physicochemical properties of the pollutants and the types of MMOFs, the adsorption mechanisms involved could be different [44-49]. Thus, it is very important to design selective MMOFs for influential removal of special pollutants. As far as we know, no MMOFs have been used for the removal of TCS and TCC in aquatic environments up to now.

Therefore, in this study, we prepared Zr-based MMOFs namely $\mathrm{Fe}_{3} \mathrm{O}_{4} @ \mathrm{SiO}_{2}$-UiO-66 by immobilization of UiO-66 onto the $\mathrm{Fe}_{3} \mathrm{O}_{4} @ \mathrm{SiO}_{2}$ particles via a simple and one-pot solvothermal method and subsequently applied for efficient removal of TCS and TCC from aqueous environments. The MMOFs were well characterized and the influence factors of adsorption performances were systematically investigated. Under the optimal adsorption conditions, the adsorption isotherms, thermodynamics and kinetics models were studied. Besides, the interference and reusability of the MMOFs were examined. The possible adsorption mechanism of the MMOFs for TCS and TCC in water was also proposed.

\section{Experimental}

\section{Materials and methods}

All chemical reagents were of at least analytical grade. Iron oxide $\left(\mathrm{Fe}_{3} \mathrm{O}_{4}\right)$ was purchased from Aladdin Reagent Co., Ltd. (Shanghai, China). Zirconium chloride $\left(\mathrm{ZrCl}_{4}\right)$, benzene-1,4-dicarboxylic acid $\left(\mathrm{H}_{2} \mathrm{BDC}\right)$ and zinc chloride $\left(\mathrm{ZnCl}_{2}\right)$ were obtained from Sinopharm Group Chemical Reagent Co., Ltd. (Shanghai, China). Methyl orange (MO) was purchased from Tianjin Guangfu Fine Chemical Research Institute (Tianjin, China). Tetraethyl orthosilicate (TEOS) was obtained from Macklin Reagent Co., Ltd. (Shanghai, China). Methanol $\left(\mathrm{CH}_{3} \mathrm{OH}\right)$ was purchased from United States Honeywell Company (USA). Sodium chloride $(\mathrm{NaCl})$, cobalt (II) chloride hexahydrate $\left(\mathrm{CoCl}_{2} \cdot 6 \mathrm{H}_{2} \mathrm{O}\right), \mathrm{N}, \mathrm{N}$-dimethylformamide (DMF) and ethanol $\left(\mathrm{CH}_{3} \mathrm{CH}_{2} \mathrm{OH}\right)$ were supplied by Shanghai Ebene Chemical Reagent Co., Ltd. (Shanghai, China). Ammonia $\left(\mathrm{NH}_{3} \cdot \mathrm{H}_{2} \mathrm{O}\right.$ ) 
was purchased from Yantai Sanhe Chemical Reagent Co., Ltd. (Shandong, China). Hydrochloric acid $(\mathrm{HCl})$ and sodium hydroxide $(\mathrm{NaOH})$ were purchased from Laiyang City Kant Chemical Co., Ltd. (Shandong, China) and Tianjin Hongyan Chemical Reagent Factory (Tianjin, China), respectively. Potassium chloride, magnesium sulfate heptahydrate and calcium chloride were supplied by Tianjin Ruijinte Chemical Reagent Co., Ltd. (Tianjin, China). Ultrapure water $\left(18.2 \mathrm{M} \Omega\right.$ ) was obtained by a model Mingche $\mathrm{D}-24^{\mathrm{UV}}$ ultra-pure water system (Millipore, France), and it was used for aqueous preparation throughout the work.

Triclosan (TCS, 97\%) and triclocarban (TCC, 98\%) were purchased from Aladdin Reagent Co., Ltd. (Shanghai, China). Their structural formula and physicochemical parameters were shown in Fig. S1. $1000 \mathrm{mg} \mathrm{L}^{-1}$ of TCS or TCC standard stock solutions were prepared by dissolving $100 \mathrm{mg}$ of TCS or TCC into $100 \mathrm{~mL}$ methanol. The stock solutions were stored at $4{ }^{\circ} \mathrm{C}$ in the dark.

Water samples were collected from Qianhan Reservoir, Wangquan Reservoir and Shipeng Reservoir, respectively. All samples were filtered through the $0.45 \mu \mathrm{m}$ filter membrane and then placed in the refrigerator at $4{ }^{\circ} \mathrm{C}$ for further analysis.

\section{Apparatus}

The X-ray diffractometer (XRD) patterns of $\mathrm{Fe}_{3} \mathrm{O}_{4}$, UiO-66 and MMOFs were measured by D8 Advance X-ray diffractometer (Bruker, USA). The size and structure of the MMOFs and $\mathrm{Fe}_{3} \mathrm{O}_{4} @ \mathrm{SiO}_{2}$ were observed by a transmission electron microscope (TEM) with FEI Tecnai G2 F20 (FEI, USA) and a SUPRA 55 scanning electron microscope with SEM ZEISS (Germany). The Fourier transform infrared (FT-IR) spectra of $\mathrm{Fe}_{3} \mathrm{O}_{4}, \mathrm{Fe}_{3} \mathrm{O}_{4} @ \mathrm{SiO}_{2}$, UiO-66, and the MMOFs were recorded in the wavenumber range of $2000-450 \mathrm{~cm}^{-1}$ using a Perkin Elmer Frontier spectrometer (Perkin Elmer, USA). The isoelectric point of the MMOFs and DLS size of $\mathrm{Fe}_{3} \mathrm{O}_{4} @ \mathrm{SiO}_{2}$ were determined using a Zeta Plus (Brookhaven, USA). Thermogravimetric analysis of the thermal stability of the MMOFs was performed using a thermogravimetric analyzer SDTQ600 (TA, USA) at a heating rate of $10^{\circ} \mathrm{C} \mathrm{min}^{-1}$ from $50^{\circ} \mathrm{C}$ to $800^{\circ} \mathrm{C}$. The Brunauer-Emmet-Teller (BET) surface area and pore volume of $\mathrm{Fe}_{3} \mathrm{O}_{4}, \mathrm{Fe}_{3} \mathrm{O}_{4} @ \mathrm{SiO}_{2}$, UiO-66, and the MMOFs were determined by $\mathrm{N}_{2}$ adsorption-desorption using a 3H-2000PS1 (BeiShiDe, China) type surface area analyzer. The magnetic hysteresis loops of the MMOFs was obtained by VSM 7307 (VSM, Lake Shore, USA) vibrating sample magnetometer with an applied field from -10,000-10,000 Oe at room temperature.

Agilent 1100 series HPLC was used to analyze the concentration of TCS and TCC. The HPLC contained a quaternary delivery pump, an auto-sampler, a diode array UV detector, and a thermostatic column. A personal computer equipped with Agilent ChemStation for HPLC was used to process the data. A ZORBAX SB- $\mathrm{C}_{18}$ column $(4.6 \times 250 \mathrm{~mm}, 5 \mu \mathrm{m})$ was used to detect the concentration of TCS and TCC at $30^{\circ} \mathrm{C}$. The sample injection volume was $10 \mu \mathrm{L}$. The test wavelength and the reference wavelength were $280 \mathrm{~nm}$ and $360 \mathrm{~nm}$, respectively. The mobile phase consisted of ultrapure water and methanol $(20: 80, \mathrm{v} / \mathrm{v})$ mixture. The flow rate was set at $1 \mathrm{~mL} \mathrm{~min}{ }^{-1}$.

\section{Synthesis of $\mathrm{Fe}_{3} \mathrm{O}_{4} @ \mathrm{SiO}_{2}-\mathrm{UiO}-66 \mathrm{MMOFs}$}

Magnetic UiO-66 was synthesized by referring to the previous literature $[50,51]$ with some necessary modifications. Herein, the $\mathrm{Fe}_{3} \mathrm{O}_{4}$ particle size was $20 \mathrm{~nm}$ in diameter, which was much smaller than the $\mathrm{Fe}_{3} \mathrm{O}_{4}$ size $(100 \mathrm{~nm})$ in the previous literature; and the concentration of MOF precursor $\mathrm{ZrCl}_{4}(59 \mathrm{mM})$ was higher than that reported $(50 \mathrm{mM})[50,51]$. Firstly, $120 \mathrm{mg}$ of $\mathrm{Fe}_{3} \mathrm{O}_{4}$ nanoparticles were sonicated in $240 \mathrm{~mL}$ ethanol for $30 \mathrm{~min}$, and then $12 \mathrm{~mL}$ of $\mathrm{NH}_{3} \cdot \mathrm{H}_{2} \mathrm{O}, 15 \mathrm{~mL}$ of ultrapure water, and $400 \mu \mathrm{L}$ of TEOS were added. The mixture was placed in a $40{ }^{\circ} \mathrm{C}$ water bath and mechanically stirred for $2 \mathrm{~h}$. The precipitates were collected with a magnet, washed three times with ultrapure water and ethanol, followed by drying in a vacuum oven for $4 \mathrm{~h}$ to obtain $\mathrm{Fe}_{3} \mathrm{O}_{4} @ \mathrm{SiO}_{2}$ particles.

In the next step, $0.436 \mathrm{~g} \mathrm{H}_{2} \mathrm{BDC}$ and $0.683 \mathrm{~g} \mathrm{ZrCl}_{4}$ were dispersed in $50 \mathrm{~mL}$ DMF. After ultrasonication for $10 \mathrm{~min}$, $\mathrm{Fe}_{3} \mathrm{O}_{4} @ \mathrm{SiO}_{2}$ was added to the mixture and dispersed uniformly. The mixture was transferred to a $100 \mathrm{~mL}$ polytetrafluoroethylene lined stainless steel autoclave and placed in an oven at $120^{\circ} \mathrm{C}$. After $24 \mathrm{~h}$, it was taken out and cooling down to room temperature. Then, the product was washed several times with DMF. Finally, $\mathrm{Fe}_{3} \mathrm{O}_{4} @ \mathrm{SiO}_{2}-\mathrm{UiO}-66$ (MMOFs) was obtained by drying product in a $150{ }^{\circ} \mathrm{C}$ oven for $12 \mathrm{~h}$.

\section{Adsorption experiments}

The different concentrations of TCS and TCC were prepared by diluting $1000 \mathrm{mg} \mathrm{L}^{-1}$ stock solutions with ultrapure water, respectively. Calibration curves were constructed for the TCS and TCC at the concentrations ranging from 0.5 to $50 \mathrm{mg} \mathrm{L}^{-1}$ in the ultrapure water solutions.

To achieve the best adsorption performances, the influence of primary factors such as the mass ratio of $\mathrm{Fe}_{3} \mathrm{O}_{4} @ \mathrm{SiO}_{2}$ and $\mathrm{ZrCl}_{4}$, sample $\mathrm{pH}$, adsorbent dosage, salt concentration and adsorption equilibrium time on the removal efficiency of TCS and TCC from the water was investigated. Adsorption experiments were carried out as follow: $20 \mathrm{~mL}$ solution of TCS $\left(20 \mathrm{mg} \mathrm{L}^{-1}\right)$ or TCC $\left(10 \mathrm{mg} \mathrm{L}^{-1}\right)$ was added into $200 \mathrm{~mL}$ conical flask and followed adding $1 \mathrm{mg}$ MMOFs with a magnetic ratio of $1: 7$. The $\mathrm{pH}$ values of the TCS and TCC sample solutions were adjusted to be 3.0. Afterwards, $\mathrm{NaCl}$ was added to the TCS solution to bring the salt concentration to $5 \mathrm{~mol} \mathrm{~L}^{-}$ 1 and no $\mathrm{NaCl}$ was added to the TCC solution. The mixture was shaken in an oscillator at $35^{\circ} \mathrm{C}$ for $25 \mathrm{~min}$, and then the adsorbents were collected by a magnet after adsorption.

Furthermore, we also examined the interference of the coexisting ions. The interfering experiment was carried out by adding the commonly found ions namely $\mathrm{K}^{+}, \mathrm{Na}^{+}, \mathrm{Ca}^{2+}$ and $\mathrm{MO}$ individual at $0,0.1,1,5$ and $10 \mathrm{mM}$, respectively. The supernatant was taken and filtered through a $0.45 \mu \mathrm{m}$ filter, and the residual amount of TCS and TCC was measured by HPLC.

The following Eq. (1) is used to calculate the adsorption capacity $q_{\mathrm{t}}$.

$q_{t}=\frac{\left(\mathrm{C}_{0}-\mathrm{C}_{t}\right) v}{m}$

Where $C_{0}\left(\mathrm{mg} \mathrm{L}^{-1}\right)$ is the initial concentration of TCS and TCC in the aqueous solution, $C_{t}\left(\mathrm{mg} \mathrm{L}^{-1}\right)$ is the concentration of TCS and TCC in the solution at time $t, v(\mathrm{~mL})$ is the volume of the aqueous solution, $m(\mathrm{mg})$ is the mass of adsorbent.

The adsorption kinetic models of TCS and TCC on MMOFs were studied at the initial concentrations of $10-50 \mathrm{mg} \mathrm{L}^{-1} .1 \mathrm{mg}$ of MMOFs was added to the solutions and placed in a shaker at $20^{\circ} \mathrm{C}$. The each concentration of TCS and TCC in water after adsorption was detected at a fixed time (from 3 to $70 \mathrm{~min}$ ). The pseudo-firstorder and pseudo-second-order kinetic models were used to analyze the adsorption kinetics of TCS and TCC on MMOFs. The following Eqs. (2) and (3) are the pseudo-first-order and the pseudo-second-order kinetic model formula.

$\ln \left(q_{e}-q_{t}\right)=\ln q_{e}-\frac{k_{1}}{2.303} t$

$\frac{t}{q_{t}}=\frac{1}{k_{2} q_{e}^{2}}+\frac{1}{q_{e}} t$ 
Where $q_{\mathrm{e}}\left(\mathrm{mg} \mathrm{g}^{-1}\right)$ is the adsorption amount in the adsorption equilibrium, $q_{\mathrm{t}}\left(\mathrm{mg} \mathrm{g}^{-1}\right)$ is the adsorption amount at time $t, \mathrm{k}_{1}$ $\left(\mathrm{min}^{-1}\right)$ is the pseudo-first-order reaction rate constant, $\mathrm{k}_{2}$ $\left(\mathrm{mg} \mathrm{g}^{-1} \mathrm{~min}^{-1}\right)$ is a pseudo-secondary reaction rate constant.

The adsorption isotherm models of TCS and TCC on MMOFs were studied at different initial concentrations from 10 to $50 \mathrm{mg} \cdot \mathrm{L}^{-1}$. The Langmuir and Freundlich isotherm models were used to describe the relationship between their adsorption capacity on MMOFs and their equilibrium concentration in water. The Eq. (4) is the Langmuir isotherm equation.

$\frac{C_{e}}{q_{e}}=\frac{1}{q_{m} b}+\frac{C_{e}}{q_{m}}$

Where $q_{\mathrm{e}}\left(\mathrm{mg} \mathrm{g}^{-1}\right)$ is the adsorption amount of TCS and TCC on the adsorbent in the equilibrium, $C_{\mathrm{e}}\left(\mathrm{mg} \mathrm{L}^{-1}\right)$ is the concentration of TCS and TCC solutions in the equilibrium, $q_{\mathrm{m}}\left(\mathrm{mg} \mathrm{g}^{-1}\right)$ is the maximum adsorption capacity of the adsorbent, and $b\left(\mathrm{~L} \mathrm{mg}^{-1}\right)$ is the Langmuir isotherm constant. The Eq. (5) is the Freundlich isotherm equation.

$\ln \mathrm{q}_{\mathrm{e}}=\ln \mathrm{K}_{\mathrm{f}}+\frac{1}{\mathrm{n}} \ln \mathrm{C}_{\mathrm{e}}$

Where $\mathrm{K}_{\mathrm{f}}\left(\mathrm{mg} \mathrm{g}^{-1}\right)$ is the Freundlich isotherm constant, and $\mathrm{n}$ is the Freundlich constant of the adsorption model related to the adsorption strength.

In order to describe the energy change in the adsorption processes of TCS and TCC, determine the driving force and direction of the adsorption process, the thermodynamic model needs to be used to calculate the adsorption thermodynamic parameters at $20^{\circ} \mathrm{C}-30^{\circ} \mathrm{C}$. The thermodynamic formulas are Eqs. (6) and (7):

$\Delta \mathrm{G}=-\mathrm{RT} \ln \mathrm{K}$

$\ln \mathrm{K}=\frac{\Delta \mathrm{S}}{\mathrm{R}}-\frac{\Delta \mathrm{H}}{\mathrm{RT}}$

Where $\Delta \mathrm{G}\left(\mathrm{kj} \mathrm{mol}^{-1}\right)$ is Gibbs free energy, $\mathrm{R}\left(\mathrm{j} \mathrm{mol}^{-1} \mathrm{~K}^{-1}\right)$ is the ideal gas constant (8.314), $T(\mathrm{~K})$ is the reaction temperature, $\mathrm{K}$ $\left(\mathrm{Lg}^{-1}\right)$ is the equilibrium adsorption constant, $\Delta H\left(\mathrm{kj} \mathrm{mol}^{-1}\right)$ is the standard enthalpy change, $\Delta S\left(\mathrm{kj} \mathrm{mol}^{-1} \mathrm{~K}^{-1}\right)$ is the standard enthalpy change.

\section{Interference study}

Considering the possible influence of inorganic ions and anion spices in environmental water on the adsorption of organic matter, interference experiments were carried out. Different concentrations of common metal ions and anion spices were added to the simulated water samples as competing ions. $1 \mathrm{mg}$ MMOFs with a magnetic ratio of $1: 7$ were added to $20 \mathrm{~mL}$ of $10 \mathrm{mg} \mathrm{L}^{-1}$ TCS and TCC solution, respectively. The $\mathrm{pH}$ of this solution was adjusted to 3.0 , and $5 \mathrm{~mol} \mathrm{~L}^{-1} \mathrm{NaCl}$ was added to the TCS solution, and there was no $\mathrm{NaCl}$ in the TCC solution. Then, add $\mathrm{K}^{+}, \mathrm{Mg}^{2+}, \mathrm{Ca}^{2+}, \mathrm{Zn}^{2+}, \mathrm{Co}^{2+}$ and MO to the solution, respectively. And set the concentration to $0,0.1,1,5$ and $10 \mathrm{~mol} \mathrm{~L}^{-1}$ to compare the results of interference experiments. Finally, the mixtures were placed in a $35^{\circ} \mathrm{C}$ shaker for $25 \mathrm{~min}$.

\section{Reusability study}

To solve the problem of adsorbent contamination and economic cost, the reusability of MMOFs was evaluated by the adsorptiondesorption process of the same adsorbent for several times. $1 \mathrm{mg}$ MMOFs with a magnetic ratio of $1: 7$ were added to $20 \mathrm{~mL}$ of $10 \mathrm{mg} \mathrm{L}^{-1}$ TCS and TCC solution, respectively. The $\mathrm{pH}$ of this solution was adjusted to 3.0 , and $5 \mathrm{~mol} \mathrm{~L}^{-1} \mathrm{NaCl}$ was added to the TCS solution, and there was no $\mathrm{NaCl}$ in the TCC solution. The mixtures were placed in a $35^{\circ} \mathrm{C}$ shaker for $25 \mathrm{~min}$. The separated MMOFs were eluted twice with $5 \mathrm{~mL}$ of ethyl acetate for 5 min each time. Then, the eluted MMOFs were placed in a vacuum oven at $70^{\circ} \mathrm{C}$ for $12 \mathrm{~h}$ and used in the next cycle of adsorption experiments.

\section{Results and discussion}

\section{Preparation of MMOFs}

Scheme 1 schematically shows the preparation of MMOFs by solvothermal synthesis process. First, surface modification of $\mathrm{Fe}_{3} \mathrm{O}_{4}$ magnetic nanoparticles (MNPs) was carried out. $\mathrm{Fe}_{3} \mathrm{O}_{4}$ MNPs with high chemical activity are easily oxidized in the air, and they have poor acid resistance and poor compatibility with other substances, which thereby affects their magnetic properties and dispersibility [48]. To effectively stabilize the $\mathrm{Fe}_{3} \mathrm{O}_{4}$ MNPs, the surface can be modified by the methods such as embedding, monomer

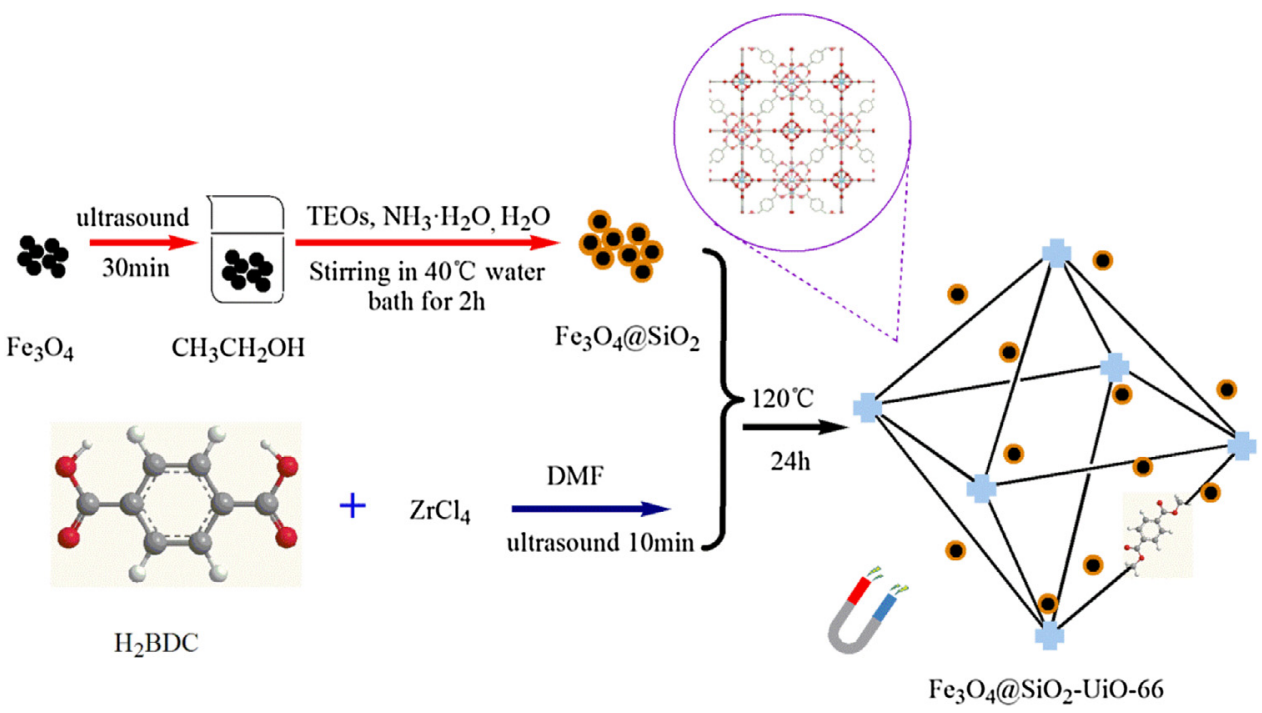

Scheme 1. Schematic illustration of the preparation of $\mathrm{Fe}_{3} \mathrm{O}_{4} @ \mathrm{SiO}_{2}-\mathrm{UiO}-66$. 
polymerization or chemical coprecipitation. Herein, the emulsion monomer polymerization method was used, which is a commonly used method for preparing magnetic polymer microspheres. The synthesized particles exhibited regular particle shape, uniform particle size distribution, and strong magnetic responses. Furthermore, the surface of $\mathrm{Fe}_{3} \mathrm{O}_{4}$ MNPs is often coated with organic small molecules, polymers, biomacromolecules, $\mathrm{SiO}_{2}$, metals, metal oxides and non-metal elements [52]. Among them, the $\mathrm{SiO}_{2}$ coating layer avoids the interaction and agglomeration between particles, improves the chemical stability of the particles, imparts hydrophilicity and biocompatibility [53], and reduces toxicity. And the thickness of the coating is easy to control during the synthesis process. $\mathrm{SiO}_{2}$ provides suitable $\mathrm{OH}$ terminal groups for further modification of $\mathrm{Fe}_{3} \mathrm{O}_{4}$ MNPs or their subsequent applications.

The UiO-66 framework is a typical Zr-MOF, made of $\mathrm{Zr}_{6} \mathrm{O}_{4}(\mathrm{OH})_{4}$ clusters and $\mathrm{H}_{2} \mathrm{BDC}$ linkers [50]. Each zirconium atom is eightcoordinated forming square-antiprismatic coordination consisting of eight oxygen atoms. One square face is formed by oxygen atoms supplied by carboxylates while the other square face is formed by oxygen atoms coming from the $\mu_{3}-\mathrm{O}$ and $\mu_{3}-\mathrm{OH}$ groups [54]. Besides, the $-\mathrm{OH}$ group on the silica can chelate with $\mathrm{Zr}_{6} \mathrm{O}_{4}(\mathrm{OH})_{4}$ clusters [51]. Next, the conjugated central $\mathrm{Zr}_{6} \mathrm{O}_{4}(\mathrm{OH})_{4}$ clusters, $\mathrm{H}_{2} \mathrm{BDC}$, and $\mathrm{Fe}_{3} \mathrm{O}_{4} @ \mathrm{SiO}_{2}$ were combined to form a magnetic UiO-66 material by one-pot solvothermal method, as shown in Scheme 1. Since the outer layer of $\mathrm{Fe}_{3} \mathrm{O}_{4} @ \mathrm{SiO}_{2}$ has -OH, the $\mathrm{O}$ atom with the metal center $\mathrm{ZrCl}_{4}$ first formed stable $\mathrm{SiO}_{2}-\mathrm{O}-\mathrm{ZrCl}_{3}$ bond [55]. Additionally, the $\mathrm{H}$ atom of the $-\mathrm{OH}$ group combined with one $\mathrm{Cl}$ atom of $\mathrm{ZrCl}_{4}$ to form a by-product $\mathrm{HCl}$. And then with the $\mathrm{H}_{2} \mathrm{BDC}$, magnetic UiO-66 was formed. The by-product $\mathrm{HCl}$ would contribute to the formation of UiO-66. As reported [51], when the concentration of MOF precursor $\left(\mathrm{ZrCl}_{4}\right)$ increases, the thickness of the outer shell of the core-shell structured magnetic UiO-66 can be increased; however, when the concentration of MOF precursor is greater than $50 \mathrm{mM}$, the precursor preferably nucleates from the seed crystal in solution and grows into larger crystals. Therefore, we chose $\mathrm{ZrCl}_{4}$ at a concentration greater than $50 \mathrm{mM}$ to form a composite rather than a core-shell structure. Also, since the smaller diameter of $\mathrm{Fe}_{3} \mathrm{O}_{4}$ was used as the MNPs to recombine with UiO-66, the proportion of MOFs per unit mass of the adsorbent was increased, thereby leading to increase in the adsorption sites for the contaminant. Several types of researches have shown that such composite materials can greatly increase the adsorption capacity of contaminants. In addition to the absorption capacity, compliance with the green chemical objectives is another important issue and should be considered. Therefore, the combination of magnetic solid phase separation technology and green synthesis method is expected to be used for the removal of organic pollutants in water.

The synthesis process and conditions of proposed MMOFs were compared with the reported synthetic methods of common MMOFs [48,56-58]. As can be seen from Table S1, the preparation of common MMOFs needs more complicated experimental equipment, more amounts of (toxic) reagents and higher temperature control. Happily, our synthesis method represents significant advantages of eco-friendliness, cost-saving, simplicity, rapidity and efficiency.

\section{Characterization of MMOFs}

The as-prepared MMOFs were fully characterized by SEM, TEM, XRD, FT-IR, TGA, BET and VSM as follows. First, the morphology and particle size of $\mathrm{Fe}_{3} \mathrm{O}_{4} @ \mathrm{SiO}_{2}$ were characterized by TEM and DLS. It can be seen from the TEM image in Fig. S2 (a) that $\mathrm{Fe}_{3} \mathrm{O}_{4} @ \mathrm{SiO}_{2}$ particles has a core-shell structure with a diameter greater than $10 \mathrm{~nm}$. It is consistent with the $12.78 \mathrm{~nm}$ particle size displayed in the DLS data in Fig. S2 (b). The SEM image in Fig. $1 \mathrm{~A}$ and the TEM image in Fig. $1 \mathrm{~B}$ demonstrated the $\mathrm{Fe}_{3} \mathrm{O}_{4}$ nanoparticles were suitably coated with a $\mathrm{SiO}_{2}$ layer to protect $\mathrm{Fe}_{3} \mathrm{O}_{4}$ from oxidation. The formed spherical nanoparticles were assembled with UiO-66

(A)
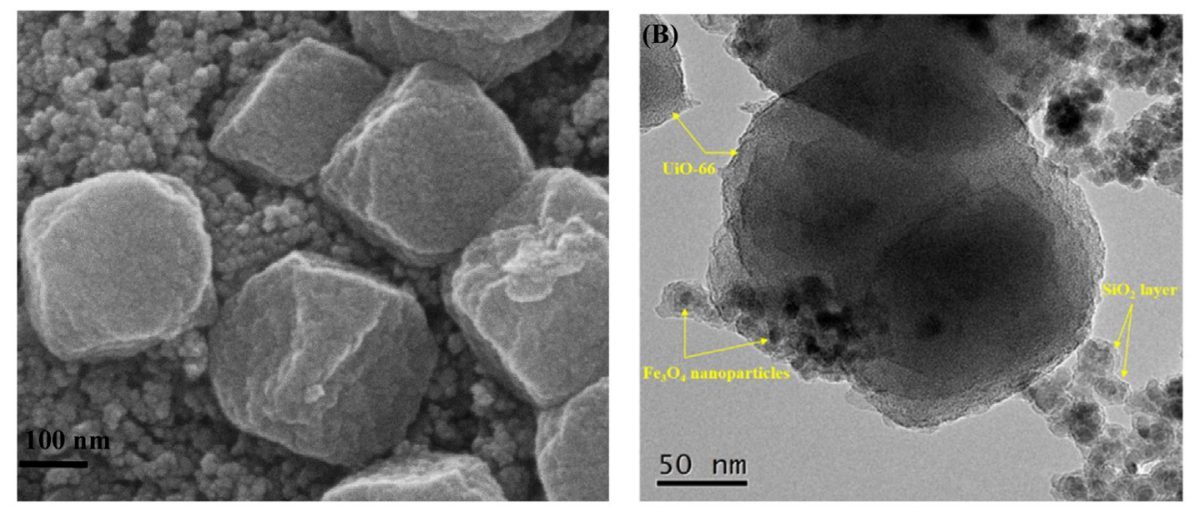

(C)

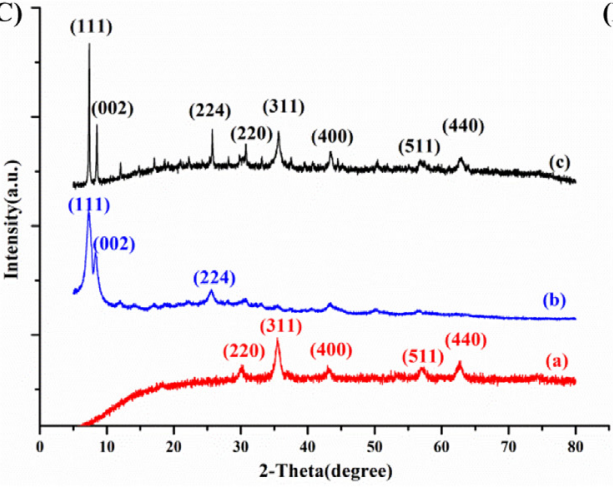

(D)

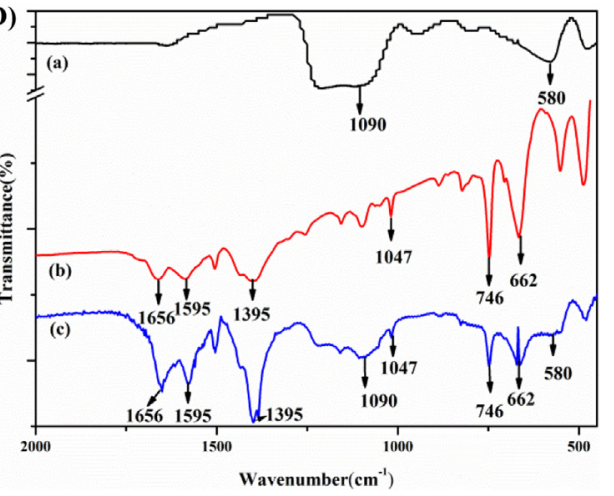

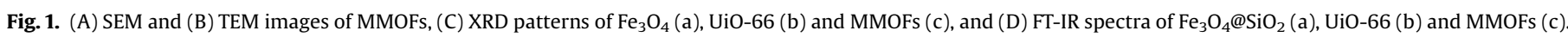


particles with cubic shape and a porous structure to form the MMOFs having a size of about $200 \mathrm{~nm}$, which provides direct evidence for the successful synthesis of the MMOFs composites.

As shown in Fig. 1C, the XRD patterns were used to characterize the crystal structures of $\mathrm{Fe}_{3} \mathrm{O}_{4}$ (a), UiO-66 (b) and MMOFs (c). In Fig. $1 \mathrm{C}(\mathrm{a}), 2 \theta=30.1^{\circ}, 35.5^{\circ}, 43.1^{\circ}, 57.0^{\circ}$ and $62.6^{\circ}$ could correspond to characteristic diffraction peaks (220), (311), (400), (511) and (440) of $\mathrm{Fe}_{3} \mathrm{O}_{4}$ particles. In Fig. $1 \mathrm{C}(\mathrm{b}), 2 \theta=7.36^{\circ}, 8.48^{\circ}$ and $25.68^{\circ}$ could be attributed to the characteristic diffraction peaks (002), (111) and (224) of UiO-66. The diffraction peaks in the XRD pattern of MMOFs matched the reported magnetic UiO-66 [50]. The prepared MMOFs contained two crystal structures of $\mathrm{Fe}_{3} \mathrm{O}_{4}$ and UiO-66. The results suggested that magnetic modification did not affect the crystal structure of the MOFs.

Fig. 1D shows the FT-IR spectra of $\mathrm{Fe}_{3} \mathrm{O}_{4} @ \mathrm{SiO}_{2}$ (a), UiO-66 (b) and MMOFs (c). In Fig. 1D (a), the peak at $580 \mathrm{~cm}^{-1}$ possibly belonged to the Fe-O-Fe band, and the broad peak near $1090 \mathrm{~cm}^{-1}$ can be designated as O-Si-O stretching vibration. For the evaluation units of UiO-66 and MMOFs, there were two kinds of $\mathrm{Zr}-\mathrm{O}$ bands; one was a $\mathrm{Zr}-\mathrm{O}-\mathrm{C}$ band, and the other one was a $\mathrm{Zr}-\mathrm{O}-\mathrm{Zr}$ band. In Fig. $1 \mathrm{D}$ (b) and (c), the peaks at 662,746 and $1047 \mathrm{~cm}^{-1}$ can be attributed to the vibration of the $\mathrm{Zr}-\mathrm{O}$ band. And the peak at $1656 \mathrm{~cm}^{-1}$ may be ascribed to residual DMF in the channels. The peaks at $1595 \mathrm{~cm}^{-1}$ and $1395 \mathrm{~cm}^{-1}$ are very likely to be associated with the in- and out-of-phase stretching modes of the carboxylate group of $\mathrm{H}_{2} \mathrm{BDC}$ [50]. These FT-IR results confirmed that MMOFs had been successfully synthesized, which are consistent with the FT-IR spectra reported [50]. Diverse functional groups existence in the MMOFs structure provided supreme binding sites for influential adsorption of targeted pollutants.

Also, TGA, BET and VSM were employed to characterize the MMOFs. The TGA results were shown in Fig. S3. When the temperature increased from room temperature to $100^{\circ} \mathrm{C}$, the mass would be lost $7.5 \mathrm{wt} \%$, which might result from the loss of surface
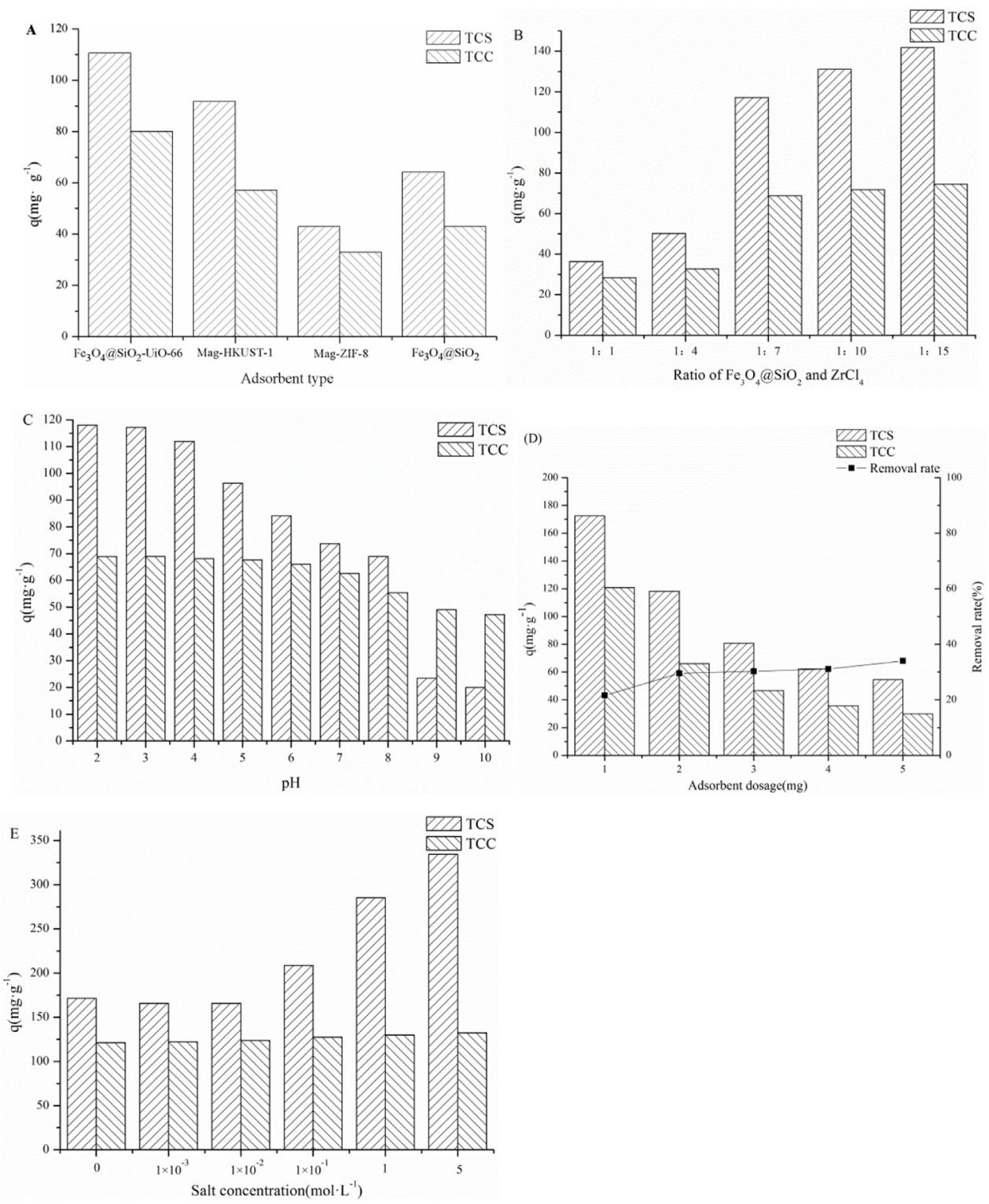

Fig. 2. Effect of (A) adsorbent type, (B) mass ratio of $\mathrm{Fe}_{3} \mathrm{O}_{4} @ \mathrm{SiO}_{2}$ to $\mathrm{ZrCl}_{4}$, (C) solution pH, (D) adsorbent dosage, and (E) salt concentration on TCS and TCC adsorption performance by MMOFs, respectively. Adsorption conditions: water bath temperature at $20^{\circ} \mathrm{C}$ and adsorption time for 20 min; (A) Water sample pH: 6.0, adsorbent dosage: $2 \mathrm{mg}$, no salt; (B) Water sample pH: 6.0, adsorbent dosage: $2 \mathrm{mg}$, adsorbent: $\mathrm{MMOFs}$, no salt; (C) Adsorbent dosage: 2 mg, adsorbent: $\mathrm{MMOFs}$, the mass ratio of Fe $\mathrm{O}_{4} @ \mathrm{SSO}_{2}$ and $\mathrm{ZrCl}_{4}: 1:$, no salt; (D) Water sample pH: 3.0, adsorbent: MMOFs, the mass ratio of $\mathrm{Fe}_{3} \mathrm{O}_{4} @ \mathrm{SiO}_{2}$ and $\mathrm{ZrCl}_{4}: 1: 7$, no salt; (E) Water sample pH: 3.0, adsorbent dosage: $1 \mathrm{mg}$, adsorbent: $\mathrm{Fe}_{3} \mathrm{O}_{4} @ \mathrm{SiO}_{2}$-UiO-66, the mass ratio of $\mathrm{Fe}_{3} \mathrm{O}_{4} @ \mathrm{SiO}_{2}$ and $\mathrm{ZrCl}_{4}: 1: 7$. 
water and bounded water molecules of MMOFs. When the temperature was increased from 100 to $450^{\circ} \mathrm{C}$, the weight loss of $\mathrm{Fe}_{3} \mathrm{O}_{4} @ \mathrm{SiO}_{2}$-UiO-66 was 12.5 wt\%, which might be caused by the loss of residual DMF solvent and the dehydroxylation of zirconium oxygen clusters. The rapid decrease in mass from 450 to $550^{\circ} \mathrm{C}$ was very likely due to the breakage of the coordination bond between the ligand and the metal, resulting in a collapse of the MOF skeleton. At a temperature higher than $550^{\circ} \mathrm{C}$, the weight loss of the material can be explained by decomposition of organic ligands and conversion to $\mathrm{ZrO}_{2}$ [59]. The TGA results demonstrated that the MMOFs had appropriate thermal stability below $350^{\circ} \mathrm{C}$ and it was consistent with that reported [51].

The BET surface area and pore volume of $\mathrm{Fe}_{3} \mathrm{O}_{4}(\mathrm{a}), \mathrm{Fe}_{3} \mathrm{O}_{4} @ \mathrm{SiO}_{2}$ (b), UiO-66 (c) and MMOFs (d) were tested based on the $\mathrm{N}_{2}$ adsorption-desorption isotherm at $77 \mathrm{~K}$ as shown in Fig. S4 and Table S2. It can be observed that the surface area of MMOFs was $372.14 \mathrm{~m}^{2} \mathrm{~g}^{-1}$ and the pore volume was $0.147 \mathrm{mLg}^{-1}$. MMOFs had higher surface area than that of $\mathrm{Fe}_{3} \mathrm{O}_{4} @ \mathrm{SiO}_{2}$ and $\mathrm{Fe}_{3} \mathrm{O}_{4}$, but smaller than that of pure UiO-66. The phenomenon indicated that UiO-66 was successfully combined with $\mathrm{Fe}_{3} \mathrm{O}_{4} @ \mathrm{SiO}_{2}$. The porosity of MMOFs significantly facilitated the mass transfer of analytes and the binding sites were more accessible to interact with pollutant species.

As shown in Fig. S5, the magnetic saturation strength of MMOFs was about $21.53 \mathrm{emug}^{-1}$, which was slightly higher than the reported $13 \mathrm{emu} \mathrm{g}^{-1}$ [47]. As seen from the inset, the MMOFs were dispersed in the water sample homogeneously and the turbid water sample can become clear quickly under an external magnetic field. Owing to high magnetic saturation strength, the MMOFs can be easily and completely isolated by consuming the least of energy without any complex equipment.

\section{Condition optimization of MMOFs based adsorption}

Factors affecting the adsorption performance mainly included the type and amount of adsorbent, the $\mathrm{pH}$ and salinity of the solution. The detailed investigation was carried out as follows.

\section{Effect of adsorbent type}

To select a suitable material as the adsorbent for TCS and TCC in water, three other adsorbents with the same magnetic-mass ratio (1:7) including mag-ZIF-8, mag-HKUST- 1 and $\mathrm{Fe}_{3} \mathrm{O}_{4} @ \mathrm{SiO}_{2}$ were prepared and used for comparison with $\mathrm{Fe}_{3} \mathrm{O}_{4} @ \mathrm{SiO}_{2}-\mathrm{UiO}-66$. Their preparation details were given in Experimental S1 and specific surface areas were listed in Table S3. As shown in Fig. 2A, the $\mathrm{Fe}_{3} \mathrm{O}_{4} @ \mathrm{SiO}_{2}-\mathrm{UiO}-66$ had the highest adsorption capacities for both TCS and TCC, which may be due to the fact that the benzene ring in the ligand of MOFs can form a neighborhood $\pi-\pi$ interaction and hydrogen bonding with TCS and TCC in favor of adsorption. Due to the existing of abundant $\mathrm{Zr}$-bound hydroxides in the nodes of $\mathrm{Zr}$ MOFs [60], they exhibited excellent performance for removal of TCS and TCC from water. Apart from this, the octahedral and tetrahedral cavities with free diameters of $11 \AA$ and $8 \AA$, respectively, which are connected with narrow triangle windows, having free diameters of 5-7 $\AA$. This unique connection renders with high surface area, large pore windows, large pores, and accessible coordinative unsaturated sites to UiO-66(Zr) [50]. Meanwhile, the highest specific surface area of $\mathrm{Fe}_{3} \mathrm{O}_{4} @ \mathrm{SiO}_{2}-\mathrm{UiO}-66$ (Table S3) provided the most adsorption sites for TCS and TCC. Mag-ZIF-8 and Mag-HKUST-1 had poor adsorption effects to TCS and TCC, possibly owing to mechanical stirring for their synthesis. The $\mathrm{Fe}_{3} \mathrm{O}_{4} @ \mathrm{SiO}_{2^{-}}$ UiO-66 was prepared via a one-pot solvothermal method, which endowed the resulted material with a tighter binding force and a

A

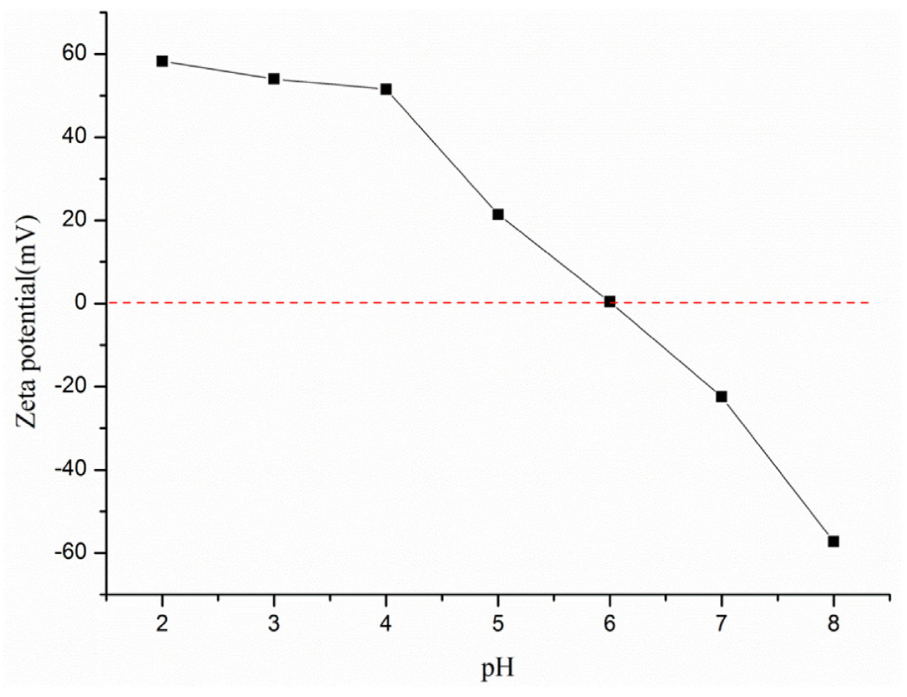

B

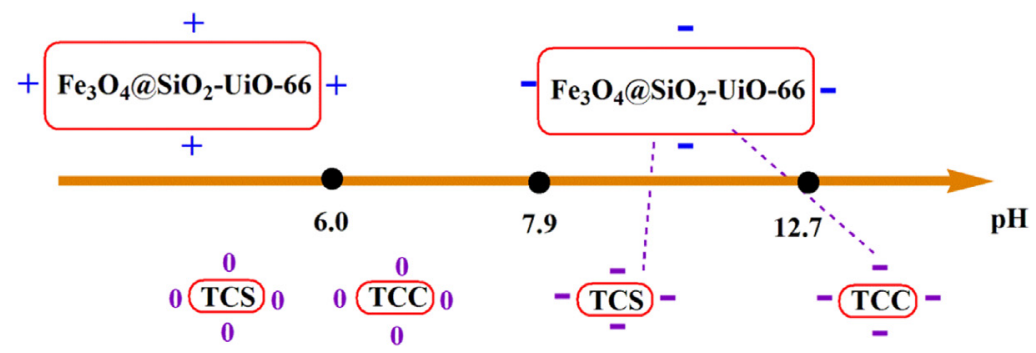

Fig. 3. (A) Zeta potential distribution of MMOFs, and (B) surface charge diagram of MMOFs, TCS and TCC at different pH values. 
higher MOF loading capacity. So, the $\mathrm{Fe}_{3} \mathrm{O}_{4} @ \mathrm{SiO}_{2}-\mathrm{UiO}-66$ had a larger specific surface area and exhibited better adsorption efficiency. This result is consistent with the report in the literature, since the specific surface area of UiO-66 $\left(861.1 \mathrm{~m}^{2} \cdot \mathrm{g}^{-1}\right)$ (Table S2) is indeed higher than ZIF-8 $\left(465.8 \mathrm{~m}^{2} \cdot \mathrm{g}^{-1}\right)$ [48] and HKUST-1 $\left(567.9 \mathrm{~m}^{2} \cdot \mathrm{g}^{-1}\right)$ [61]. It is well-known larger specific surface area provides more adsorption sites for pollutants trapping, thereby increasing the adsorption capacity.

On the other hand, as we know, compounds containing $\mathrm{Cl}$ atoms are considered as hard bases, while metal center $\mathrm{Zr}$ atoms in $\mathrm{Fe}_{3} \mathrm{O}_{4} @ \mathrm{SiO}_{2}-\mathrm{UiO}-66$ are considered as hard acids. According to hard-soft-acid-base theory, "hard" acids react faster with "hard" bases to form stronger coordination bonds [62]. Therefore, $\mathrm{Fe}_{3} \mathrm{O}_{4} @ \mathrm{SiO}_{2}$-UiO-66 was more easily and stably bonded to TCS and TCC, and exhibited good adsorption performance. However, the metal center atoms in Mag-ZIF-8 and Mag-HKUST-1 are Zn and $\mathrm{Cu}$, respectively, which are considered as soft acids [63], and it is difficult to bond with the hard bases of TCS and TCC, leading to low adsorption capacity. Also, it contains $\mathrm{Fe}_{3} \mathrm{O}_{4} @ \mathrm{SiO}_{2}$ in $\mathrm{Fe}_{3} \mathrm{O}_{4} @ \mathrm{SiO}_{2}-$ UiO-66, which can form hydrogen bonding force with TCS and TCC to achieve adsorption effect. This is also the reason why $\mathrm{Fe}_{3} \mathrm{O}_{4} @ \mathrm{SiO}_{2}$ had certain removal ability for TCS and TCC. Therefore, $\mathrm{Fe}_{3} \mathrm{O}_{4} @ \mathrm{SiO}_{2}-\mathrm{UiO}-66$ was chosen as the adsorbent for the removal of TCS and TCC.

\section{Effect of mass ratio of $\mathrm{Fe}_{3} \mathrm{O}_{4} @ \mathrm{SiO}_{2}$ to $\mathrm{ZrCl}_{4}$}

In the preparation of the MMOFs, not only the high adsorption capacity for TCS and TCC is needed to be ensured, but also the composite material must also have appropriate magnetism to allow the adsorbent to be quickly separated from the solution. In this experiment, a series of composite materials with mass ratios $\left(\mathrm{Fe}_{3} \mathrm{O}_{4} @ \mathrm{SiO}_{2}: \mathrm{ZrCl}_{4}\right)$ of $1: 1,1: 4,1: 7,1: 10$ and $1: 15$ were synthesized. The adsorption capacities for TCS and TCC in water with different magnetic mass ratios of $\mathrm{Fe}_{3} \mathrm{O}_{4} @ \mathrm{SiO}_{2}-\mathrm{UiO}-66$ were compared. As shown in Fig. 2B, when the mass ratio was decreased from 1:7,1:10 to $1: 15$, the adsorption capacity increased; however, the magnetic strength of the composite material decreased (Fig. S6). All the prepared MMOFs had a remarkable magnetic property that can be fast separated from the sample solution within $30 \mathrm{~s}$. Therefore, after comprehensive consideration, for the further experiments, the ratio of 1:7 for $\mathrm{Fe}_{3} \mathrm{O}_{4} @ \mathrm{SiO}_{2}$ to $\mathrm{ZrCl}_{4}$ was used for preparing $\mathrm{Fe}_{3} \mathrm{O}_{4} @ \mathrm{SiO}_{2}-\mathrm{UiO}-66 \mathrm{MMOFs}$ as the adsorbent.

\section{Effect of $\mathrm{pH}$}

In the adsorption experiments, the $\mathrm{pH}$ value of the water sample has a noticeable role in the removal yield. It not only changes the ionic or neutrality state of the target compounds but also changes the surface charge of the adsorbent, promotes or inhibits the interaction between the adsorbate and the adsorbent, and thus affects the adsorption capacity and performance. As shown in Fig. $2 \mathrm{C}$, when the $\mathrm{pH}$ of the water sample was between
2.0 and 6.0, the adsorption capacity of TCS didn't change significantly. When the $\mathrm{pH}$ value was higher than 8.0 , the adsorption capacity decreased rapidly. To explain this phenomenon, the zeta potentials of MMOFs were tested. As seen in Fig. 3A, the isoelectric point of MMOFs was 6.0. This means that when the $\mathrm{pH}$ was lower than the 6.0, the net charge of MMOFs was positive; at $\mathrm{pH}$ higher than 6.0, the net charge of MMOFs was negative. On the other hand, the $p K a$ value of TCS needed to be considered. Since the $p$ Ka value of TCS is 7.9, when the $\mathrm{pH}$ was higher than 8.0, TCS existed as anion species. Consequently, there was an electrostatic repulsion between the negatively charged MMOFs and TCS, which would reduce the adsorption efficiency of TCS. Since the $p$ Ka value of TCC is 12.7, when the pH of the water sample is lower than the pKa value, TCC was in the molecular form [23]. Fig. 3B shows the distribution of surface charge of MMOFs and TCS or TCC at different $\mathrm{pH}$ values, providing a basis for exploring the effect of $\mathrm{pH}$ on the adsorption of TCS or TCC by MMOFs. Besides, the phenolic hydroxyl group in the TCS structure and the $\mathrm{H}$ atoms in the amide group in the TCC structure can serve as hydrogen bond donor, and the $\mathrm{O}$ atom on MMOFs can act as a hydrogen bond acceptor to form a hydrogen bond force. When the $\mathrm{pH}$ value was higher than the $\mathrm{pKa}$ of object compounds, the force of the hydrogen bond was weakened. For both TCS and TCC, the adsorption capacities were higher at $\mathrm{pH}$ 2.0-3.0 than that at other $\mathrm{pH}$ values. Therefore, the $\mathrm{pH}$ 3.0 was chosen for the subsequent experiments.

\section{Effect of adsorbent dose}

It is always ideal that by least amount of adsorbent, maximum removal performance is achieved, since the waste generation as well as the cost of the process is reduced. In this regard, we investigated the changes in adsorption capacity of $\mathrm{Fe}_{3} \mathrm{O}_{4} @ \mathrm{SiO}_{2}-$ UiO-66 for TCS and TCC by adding $1-5 \mathrm{mg}$ of the adsorbent. As is shown in Fig. 2D, the adsorption capacities continuously reduced, and the removal rate increased slowly. This might be for the reason that the adsorption amount per unit of adsorbent would decrease as the amount of MMOFs increased when the initial concentration of TCS and TCC (the total amount of TCS and TCC in water) was fixed. Considering the cost increase of the experiment with the increase of the adsorbent dosage, $1 \mathrm{mg}$ MMOFs was used in the latter experiments.

\section{Effect of salt concentration}

Different concentrations of $\mathrm{NaCl}$ solutions were used to study the effect of salt concentration on the adsorption performances of TCS and TCC. The results in Fig. 2E showed that the adsorption capacity of TCS significantly increased when the salt concentration increased from 0 to $5 \mathrm{~mol} \mathrm{~L}^{-1}$. When $\mathrm{NaCl}$ solution was added, $\mathrm{NaCl}$ and TCS would compete for solvent molecules; $\mathrm{NaCl}$ is more capable of competing for solvent molecules, which causes solvent molecules to migrate from TCS to $\mathrm{NaCl}$, thereby reducing the solubility of TCS. Therefore, TCS would be more inclined to be
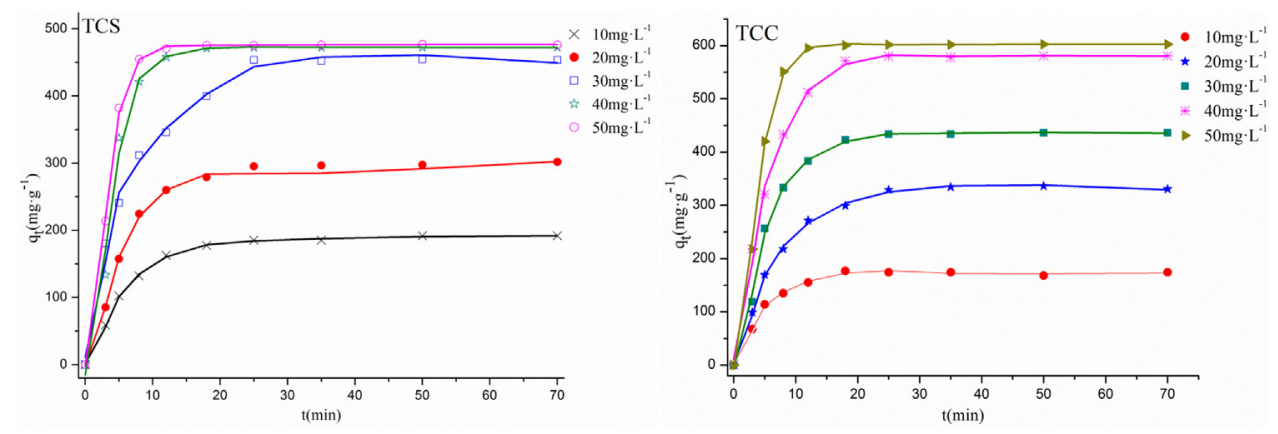

Fig. 4. Kinetic binding curves for the adsorption of TCS and TCC at different concentrations. 
Table 1

Kinetic model parameters of TCS and TCC adsorption on MMOFs.

\begin{tabular}{|c|c|c|c|c|c|c|c|}
\hline & \multirow{2}{*}{$\begin{array}{l}\mathrm{C}_{0} \\
\left(\mathrm{mg} \mathrm{L}^{-1}\right)\end{array}$} & \multicolumn{3}{|c|}{ Pseudo-first-order model } & \multicolumn{3}{|c|}{ Pseudo-second-order model } \\
\hline & & $\mathrm{k}_{1}\left(\min ^{-1}\right)$ & $\mathrm{q}_{\mathrm{e}}\left(\mathrm{mg} \mathrm{g}^{-1}\right)$ & $\mathrm{R}^{2}$ & $\mathrm{k}_{2}$ & $\mathrm{q}_{\mathrm{e}}\left(\mathrm{mg} \mathrm{g}^{-1}\right)$ & $\mathrm{R}^{2}$ \\
\hline \multirow[t]{5}{*}{ TCS } & 10 & 0.24449 & 143.96929 & 0.90812 & 0.00104 & 208.330 & 0.99518 \\
\hline & 20 & 0.18012 & 170.42069 & 0.73492 & 0.00066 & 324.675 & 0.99121 \\
\hline & 30 & 0.26093 & 398.72422 & 0.98083 & 0.00046 & 492.611 & 0.99695 \\
\hline & 40 & 0.79304 & 716.31499 & 0.98075 & 0.00151 & 490.196 & 0.99746 \\
\hline & 50 & 0.87942 & 701.49937 & 0.91631 & 0.00072 & 500.000 & 0.98878 \\
\hline \multirow[t]{5}{*}{ TCC } & 10 & 0.40535 & 172.97205 & 0.98873 & 0.00215 & 181.820 & 0.99534 \\
\hline & 20 & 0.34478 & 375.06525 & 0.98881 & 0.00055 & 364.964 & 0.99278 \\
\hline & 30 & 0.40247 & 407.67896 & 0.93866 & 0.00053 & 471.698 & 0.98983 \\
\hline & 40 & 0.44227 & 535.45669 & 0.83567 & 0.00076 & 628.931 & 0.99461 \\
\hline & 50 & 0.50592 & 341.25159 & 0.85949 & 0.00048 & 621.120 & 0.99573 \\
\hline
\end{tabular}

adsorbed due to the salting-out effect [64]. However, when the concentration of salt increased from 0 to $5 \mathrm{~mol} \mathrm{~L}^{-1}$, the adsorption capacity of TCC increased slightly. This may be because TCC and MMOFs form an internal surface complex through a coordination bond, and this coordination was not sensitive to ionic strength [65]. Therefore, the concentration of $\mathrm{NaCl}$ for TCS adsorption experiment was chosen to be $5 \mathrm{~mol} \mathrm{~L}^{-1}$, and for TCC no $\mathrm{NaCl}$ was added.

In summary, the optimal adsorption conditions were as below, $1 \mathrm{mg} \mathrm{Fe}_{3} \mathrm{O}_{4} @ \mathrm{SiO}_{2}-\mathrm{UiO}-66$ MMOFs with a magnetic mass ratio of $1: 7$, a pH of 3.0 for the water sample, a solution of $5 \mathrm{~mol} \mathrm{~L}^{-1} \mathrm{NaCl}$ in the TCS solution, and no $\mathrm{NaCl}$ in the TCC solution.

\section{Kinetic study}

Under the above optimal adsorption conditions, the adsorption kinetics and the effect of adsorption time were investigated. Fig. 4 shows the equilibrium time of MMOFs for TCS and TCC solutions with an initial concentration of $10-50 \mathrm{mg} \mathrm{L}^{-1}$. Within $10 \mathrm{~min}$, the adsorption amount increased rapidly with adsorption time increasing owing to vacant binding sites, and then gradually reached equilibrium by saturation of adsorbent. The equilibrium time of the adsorption experiment was $25 \mathrm{~min}$, which is much lower than that of other MOFs $[58,66]$.

The adsorption process of TCS and TCC by MMOFs was analyzed using the pseudo-first-order (Eq. (2)) and pseudo-second-order (Eq. (3)) kinetic models and results were listed in Table 1. As shown in Fig. S7 and S8, the measured linear correlation coefficient $\left(\mathrm{R}^{2}\right)$ of the pseudo-second-order kinetic model was closer to 1 that is higher than the $\mathrm{R}^{2}$ value determined by the pseudo-first-order kinetic model. The $q_{\mathrm{e}}$ values calculated by the pseudo-secondorder kinetic model were closer to the experimental $q_{\mathrm{e}}$ values. Thus, the pseudo-second-order kinetic model provided a better fitting than the pseudo-first-order kinetic model. These results demonstrated that the adsorption of TCS and TCC on MMOFs was mainly chemical adsorption [67].

\section{Adsorption isotherms}

The adsorption isotherm model is used to describe the distribution ratio in the solid-liquid phase during adsorption equilibrium. In this study, the Langmuir (Eq. (4)) and Freundlich (Eq. (5)) isotherm models were used to describe the relationship between the adsorption capacity of TCS and TCC on MMOFs and their equilibrium concentrations in water, as shown in Fig. S9. The Langmuir model assumes that the adsorption behavior is a single layer, and occurs on a uniform surface, as well as all adsorbents have the same force on the adsorbate. The Freundlich isotherm model is generally suitable for heterogeneous adsorption surfaces with multiple layers of adsorption. The parameters of the Langmuir and Freundlich isotherm models were shown in Table S4. The $\mathrm{R}^{2}$ value of the Langmuir isotherm model was greater than the Freundlich model. This demonstrated Langmuir was more suitable than Freundlich to express the adsorption model of TCS and TCC on MMOFs. It could be considered that such adsorption might be monolayer adsorption, and there was no interaction force between the adsorbed molecules [50]. In addition, it could be considered to reach a saturated state when the adsorption sites were occupied.

The saturated adsorption capacities of TCS and TCC calculated by the Langmuir adsorption isotherm model were $497.51 \mathrm{mg} \mathrm{g}^{-1}$ and $621.12 \mathrm{mg} \mathrm{g}^{-1}$, respectively. The calculated results were basically consistent with those obtained from the experimental results (476.27 $\mathrm{mgg}^{-1}$ and $602.40 \mathrm{mg} \mathrm{g}^{-1}$ for TCS and TCC, respectively). Good agreement between experimental and calculated results verified that the Langmuir adsorption isotherm model was suitable for the adsorption of TCS and TCC on the MMOFs. The saturated adsorption capacities of TCS on MMOFs were extremely higher than that on non-magnetic UiO-66 reported $\left(98 \mathrm{mg} \mathrm{g}^{-1}\right)$ [58]. High magnetic saturation strength along with the excellent binding capacity made the MMOFs as a supreme versatile adsorbent for influential uptake of pollutants in order to purify the environment water.

\section{Thermodynamic analysis}

The adsorption thermodynamic fitting curves of TCS and TCC at 288, 298 and $308 \mathrm{~K}$ were shown in Fig. S10 and corresponding parameters were listed in Table 2 . The results showed $\Delta \mathrm{H}$ and $\Delta \mathrm{S}$ had positive values, while $\Delta \mathrm{G}$ had negative values and the absolute value of $\Delta \mathrm{G}$ increased with the increase of temperature. It would be considered that the adsorption was a spontaneous endothermic process and the increase of the temperature facilitated the adsorption.

\section{Possible adsorption mechanism}

The adsorptive removal of TCS and TCC from the water by the MMOFs might be attributed to the combined actions of hydrogen bonding, hydrophobic interaction, $\pi-\pi$ interaction and coordination, as schematically illustrated in Fig. 5. It is worth mentioning the highest adsorption capacity was achieved at $\mathrm{pH}$ 3.0, possibly owing to that no electrostatic repulsion occurred between the adsorbent and the adsorbate at $\mathrm{pH}$ 3.0. At this time, the effect of the hydrophobic force on the removal efficiency was lower, and $-\mathrm{Cl}$, $-\mathrm{C}-\mathrm{O}-\mathrm{C}-$ and $-\mathrm{C}=\mathrm{O}$ groups in the TCS and TCC molecules might form stable coordination bonds with the open sites of $\mathrm{Zr}$ in the $\mathrm{Fe}_{3} \mathrm{O}_{4} @ \mathrm{SiO}_{2}$-UiO-66 structure [50]. Based on the presence of a few functional groups on the MMOFs and active sites for generating hydrogen bonding (phenolic and ether groups) of TCS and TCC, hydrogen bonding might be recommended as an effective adsorption mechanism. Hydrogen bonding is the main driving 
Table 2

Thermodynamic parameters of TCS and TCC adsorption on MMOFs.

\begin{tabular}{|c|c|c|c|c|c|c|}
\hline & $\mathrm{T}(\mathrm{K})$ & $\ln K$ & $\Delta \mathrm{G}\left(\mathrm{kj} \cdot \mathrm{mol}^{-1}\right)$ & $\Delta \mathrm{H}\left(\mathrm{kj} \mathrm{mol}^{-1}\right)$ & $\Delta \mathrm{S}\left(\mathrm{kj} \mathrm{mol}^{-1} \mathrm{~K}^{-1}\right)$ & $\mathrm{R}^{2}$ \\
\hline \multirow[t]{3}{*}{ TCS } & 288 & 2.741965 & -6.7684 & 62.87 & 0.2418 & 0.9715 \\
\hline & 298 & 3.873290 & -9.1864 & & & \\
\hline & 308 & 4.441272 & -11.6044 & & & \\
\hline \multirow[t]{3}{*}{ TCC } & 288 & 2.038702 & -4.8028 & 43.61 & 0.1681 & 0.9910 \\
\hline & 298 & 2.553122 & -6.4838 & & & \\
\hline & 308 & 3.223403 & -8.1648 & & & \\
\hline
\end{tabular}

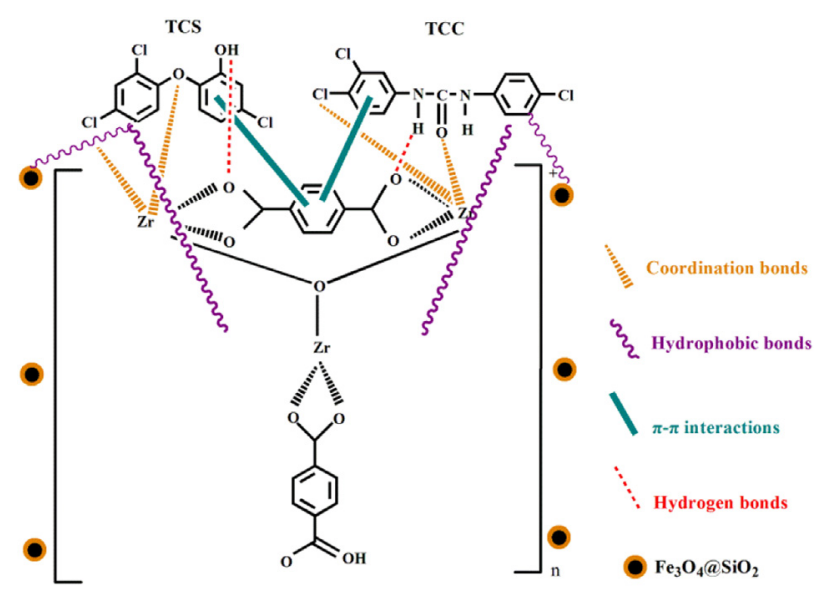

Fig. 5. Possible adsorption mechanism of TCS and TCC on MMOFs.

force for MMOFs to adsorb TCS and TCC in a wide $\mathrm{pH}$ range [68]. In particular, the adsorption results of $\mathrm{Fe}_{3} \mathrm{O}_{4} @ \mathrm{SiO}_{2}$ shown in Fig. $2 \mathrm{~A}$ may also be due to the hydrogen bonding force between $\mathrm{O}$ atoms in the $\mathrm{SiO}_{2}$ layer and TCS or TCC [69]. By increasing pH of sample solution, the saturation adsorption of TCS and TCC decreased gradually. This may be due to the effect of $\mathrm{pH}$ on deprotonation, which suppresses the efficiency of the hydrogen bonding [70]. However, when the $\mathrm{pH}$ of the sample solution is higher than the isoelectric point of the adsorbent, the saturated adsorption capacities of MMOFs for TCS and TCC were still 30\% and 65\%, respectively. The benzene rings in the adsorbent and target adsorbates can induce $\pi-\pi$ interaction [48]. This is consistent with the results in Fig. 2C. Therefore, very likely, hydrogen bonding, $\pi-\pi$ interaction and coordination coexist in the present acidic aqueous solution (Fig. 5), while the adsorption efficiency is significantly reduced by the influence of electrostatic repulsion in the alkaline aqueous solution.

\section{Anti-interference examination of the MMOFs}

Considering that commonly co-existing metal ions and anion species in water may affect the adsorption of TCS and TCC by MMOFs, an anti-interference examination was conducted by adding different concentrations of common metal ions and anion species, including $\mathrm{K}^{+}, \mathrm{Mg}^{2+}, \mathrm{Ca}^{2+}, \mathrm{Zn}^{2+}, \mathrm{Co}^{2+}$ and MO. As seen in Fig. S11, the metal ions had no significant effect on the adsorption capacities of MMOFs, which indicated the metal ions didn't compete with the adsorption sites of MMOFs towards TCS and TCC. At the same time, Fig. S12 shows that the addition of anion spices (MO) had no significant effect on the adsorption of TCS and TCC by the MMOFs. This may be because the adsorption of TCS and TCC on the MMOFs was mainly exclusive, and there was no electrostatic attraction. These results indicated that the MMOFs owned excellent selectivity for TCS and TCC adsorption with high antiinterference ability.

\section{Reusability of the MMOFs}

Reusability is considered to be one of the important criteria for practical applications of adsorbents since reusability is directly related to the cost-effectiveness of an adsorption process. The reusability of MMOFs was evaluated by using several cycles of adsorption and desorption of target species. Since TCS and TCC are hydrophobic compounds, the same hydrophobic ethyl acetate was used to elute the fungicides from MMOFs. As shown in Fig. 6, within 11 times of repeated use, the adsorption capacities of MMOFs decreased negligibly (less than $20 \%$ of the initial adsorption capacity). This indicated that the MMOFs can be reused at least 11 times through the adsorption-desorption process. Fig. S13 shows the morphologies of the MMOFs crystals before adsorption (a), and after 11 adsorption-desorption cycles for TCS (b) and for TCC (c). It can be seen that the MMOFs still maintained a cube shape of $200 \mathrm{~nm}$ and the surface was compounded with $\mathrm{Fe}_{3} \mathrm{O}_{4} @ \mathrm{SiO}_{2}$. Fig. S14 shows FT-IR structural diagrams of the MMOFs before adsorption (a), 11 adsorptiondesorption cycles for TCS (b) and for TCC (c). As seen, the regenerated MMOFs still possessed the corresponding peaks of Fe$\mathrm{O}-\mathrm{Fe}, \mathrm{O}-\mathrm{Si}-\mathrm{O}, \mathrm{Zr}-\mathrm{O}-\mathrm{C}, \mathrm{Zr}-\mathrm{O}-\mathrm{Zr}, \mathrm{C}=\mathrm{O}$, and $\mathrm{C}=\mathrm{C}$ bonds. Fig. $\mathrm{S} 15$ displays the hysteresis loop diagram of MMOFs after 11 cycles of adsorption-desorption, and its magnetic saturation intensity remained greater than $20 \mathrm{emu} \mathrm{g}^{-1}$, which is approximately similar to that of fresh MMOFs before adsorption. These results indicated the similarity and durability of the structure of the regenerated MMOFs to the original MMOFs. Thus, the elimination of pollutants by employing MMOFs benefited from the profits of waste prevention, cost-effectiveness, lower energy consumption, durability, facility, and rapidity.

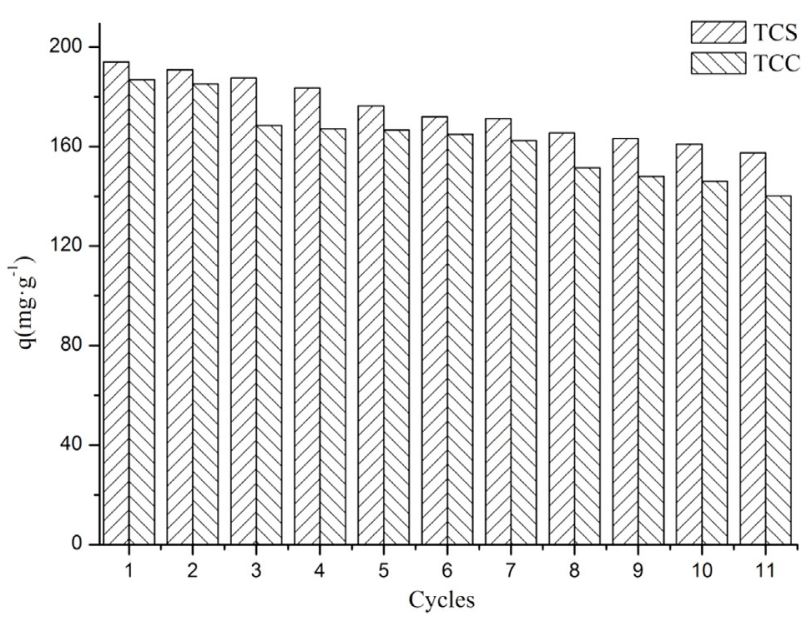

Fig. 6. Reusability of MMOFs. 
Table 3

Comparison of adsorption parameters for TCS and TCC adsorption on MMOFs with those on other adsorbents.

\begin{tabular}{|c|c|c|c|c|c|c|}
\hline \multirow[t]{2}{*}{ Adsorbent } & \multirow[t]{2}{*}{ TCS/TCC } & \multicolumn{2}{|c|}{ Adsorption condition } & \multirow{2}{*}{$\begin{array}{l}\text { Adsorption capacity } \\
\left(\mathrm{mg} \mathrm{g}^{-1}\right)\end{array}$} & \multirow[t]{2}{*}{ Equilibrium time $(\mathrm{h})$} & \multirow[t]{2}{*}{ Ref. } \\
\hline & & $\overline{\mathrm{pH}}$ & $\mathrm{NaCl}\left(\mathrm{mol} \mathrm{L}^{-1}\right)$ & & & \\
\hline $\mathrm{CNTs}^{\mathrm{a}}$ & TCS & 2.5 & 0.035 & 245.47 & 2 & {$[22]$} \\
\hline MIL-101 ${ }^{\mathrm{b}}$ & TCS & 5 & - & 130 & - & {$[24]$} \\
\hline Cetylpyridinium bromide modified natural zeolite & TCS & 6 & - & 46.95 & 8.3 & [19] \\
\hline Activated carbon & TCS & 3 & 0.1 & 70.42 & 6 & {$[21]$} \\
\hline Surfactant modified montmorillonite & TCS & 7 & - & 133 & 2.5 & [20] \\
\hline \multirow[t]{2}{*}{$\mathrm{Fe}_{3} \mathrm{O}_{4} @ \mathrm{SiO}_{2}-\mathrm{UiO}-66$} & TCS & 3 & 5 & 476.27 & 0.4 & This work \\
\hline & TCC & & None & 602.4 & & \\
\hline
\end{tabular}

a CNTs: carbon nanotubes; CNTs-OH: hydroxyl modified carbon nanotubes; CNTs-COOH: carboxyl modified carbon nanotubes.

b MIL-101: metal organic framework material MIL-101; MIL-101-OH: ethanolamine modified MIL-101; MIL-101-(OH) ${ }_{3}$ : triethanolamine modified MIL-101.

\section{Application of the MMOFs to environmental water samples}

To evaluate the applicability of MMOFs for the real water treatment, its adsorption capacity for TCS and TCC in three kinds of environmental water samples was also investigated. Water samples were spiked with TCS and TCC at concentration levels of $20 \mathrm{mg} \cdot \mathrm{L}^{-1}$ and $10 \mathrm{mg} \cdot \mathrm{L}^{-1}$, respectively, and then adsorption experiments were performed under the same experimental conditions. Related experimental data were listed in Table S5. As can be seen, the adsorption capacities of MMOFs were in the range of $437.3-462.9 \mathrm{mg} \cdot \mathrm{g}^{-1}$ and $556.0-591.1 \mathrm{mg} \cdot \mathrm{g}^{-1}$ for TCS and TCC, respectively. Compared with the adsorption capacities in pure water samples (476.27 and $602.40 \mathrm{mg} \cdot \mathrm{g}^{-1}$, respectively), there is no significant reduction. Therefore, the prepared MMOFs exhibited satisfactory applicability for actual environmental water purification.

Comparison of the adsorption efficiencies with other adsorbents for TCS and TCC

The adsorbent performances of our prepared MMOFs for TCS and TCC removal were compared with some other adsorbents reported [19-22,24], as shown in Table 3. Based on a comprehensive comparison, the MMOFs in the present study show the highest adsorption capacity (476.27 $\mathrm{mg} \mathrm{g}^{-1}$ and $602.40 \mathrm{mg} \mathrm{g}^{-1}$ for TCS and TCC, respectively), the shortest adsorption equilibrium time $(0.4 \mathrm{~h})$ and outstanding reusability. Additionally, because of desirable magnetic properties, it is easier to separate from the water and realize recycling than non-magnetic adsorbents. The proposed MMOFs in the current work can be reused after elution with ethyl acetate for $10 \mathrm{~min}$, and after 11 cycles the saturated adsorption capacities were more than $80 \%$ of initial adsorption capacities. Such excellent recyclability can save energy, time, and chemicals, as well as provide high potential for large scale application. Therefore, our present MMOFs have a promising upcoming for the removal of fungicides in water.

\section{Conclusions}

In this work, we prepared MMOFs material by a simple and onepot solvothermal method and successfully applied it for the adsorption removal of TCS and TCC in water. The prepared MMOFs had uniform morphology, good thermal stability, and remarkable magnetic properties. Moreover, the MMOFs also exhibited remarkable advantages such as short adsorption equilibrium time, high adsorption capacity, and simple magnetic separation in the removal of TCS and TCC. The adsorption process was a spontaneous endothermic process and was consistent with the Langmuir adsorption isotherm model and the pseudo-second-order kinetic model. The adsorption mechanism of MMOFs for TCS and TCC in water can be attributed to the combined effects of the $\pi-\pi$ conjugate, hydrogen bonding, hydrophobic interaction and coordination. The MMOFs material can be effectively regenerated by recycling it over 11 times. Given the combined advantages of magnetic $\mathrm{Fe}_{3} \mathrm{O}_{4}$ and $\mathrm{UiO}-66$, we foresee that this magnetic adsorbent has great potential for removing TCS and TCC from environmental waters.

\section{Author contributions}

The manuscript was written through contributions of all authors. All authors have given approval to the final version of the manuscript.

\section{Conflict of interests}

The authors declare that they have no known competing financial interests or personal relationships that could have appeared to influence the work reported in this paper.

\section{Declaration of Competing Interest}

The authors report no declarations of interest.

\section{Acknowledgment}

The authors greatly acknowledge the support from the Natural Science Foundation of Shandong Province of China (ZR2019MB046), the National Natural Science Foundation of China (21976099, 21876199), the Chinese Academy of Sciences President's International Fellowship Initiative (2019PC0050), and the Taishan Scholar Project Special Funding (ts20190962).

\section{Appendix A. Supplementary data}

Supplementary material related to this article can be found, in the online version, at doi:https://doi.org/10.1016/j.jiec.2020.0 7.010 .

\section{References}

[1] K. Delhiraja, K. Vellingiri, D.W. Boukhvalov, L. Philip, Ind. Eng. Chem. Res. 58 (2019) 2899.

[2] E. Archer, B. Petrie, B. Kasprzyk-Hordern, G.M. Wolfaardt, Chemosphere 174 (2017) 437.

[3] J. Wilkinson, P.S. Hooda, J. Barker, S. Barton, J. Swinden, Environ. Pollut. 231 (2017) 954.

[4] M. Patel, R. Kumar, K. Kishor, T. Mlsna, C.U. Pittman, D. Mohan, Chem. Rev. 119 (2019) 3510.

[5] L.A. Geer, B.F.G. Pycke, J. Waxenbaum, D.M. Sherer, O. Abulafia, R.U. Halden, J. Hazard. Mater. 323 (2017) 177.

[6] X.L. Qiao, X.D. Zheng, Q. Xie, X.H. Yang, J. Xiao, W.F. Xue, J.W. Chen, J. Hazard. Mater. 275 (2014) 210.

[7] Z.F. Chen, G.G. Ying, Y.S. Liu, Q.Q. Zhang, J.L. Zhao, S.S. Liu, J. Chen, F.J. Peng, H.J Lai, C.G. Pan, Water Res. 58 (2014) 269. 
[8] A.B. Dann, A. Hontela, J. Appl. Toxicol. 31 (2011) 285.

[9] J.M. Brausch, G.M. Rand, Chemosphere 82 (2011) 1518.

[10] A.D. Dayan, Food Chem. Toxicol. 45 (2007) 125.

[11] A. Novo, S. Andre, P. Viana, O.C. Nunes, C.M. Manaia, Water Res. 47 (2013) 1875

[12] Y. Yang, Y.S. Ok, K.H. Kim, E.E. Kwon, Y.F. Tsang, Sci. Total Environ. 596 (2017) 303.

[13] L. Wang, Y.L. Liu, C. Wang, X.D. Zhao, G.D. Mahadeva, Y.C. Wu, J. Ma, F. Zhao, J. Hazard. Mater. 344 (2018) 669.

[14] D.G. Lee, F.M. Zhao, Y.H. Rezenom, D.H. Russell, K.H. Chu, Water Res. 46 (2012) 4226.

[15] K. Murugesan, V. Bokare, J.R. Jeon, E.J. Kim, Y.S. Chang, Bioresource Technol. 102 (2011) 6019.

[16] M. Hwangbo, E.C. Claycomb, Y.N. Liu, T.E.G. Alivio, S. Banerjee, K.H. Chu, Sci. Total Environ. 649 (2019) 1189.

[17] M. Martinez-Zapata, C. Aristizabal, G. Penuela, J. Photoch. Photobio. A 251 (2013) 41.

[18] H.P. Gao, J.B. Chen, Y.L. Zhang, X.F. Zhou, Chem. Eng. J. 306 (2016) 522.

[19] C. Lei, Y.Y. Hu, M.Z. He, Chem. Eng. J. 219 (2013) 361.

[20] B. Liu, J.X. Lu, X. Yu, B. Yang, X.Y. Wang, R.C. Sun, J. Colloid Interf. Sci. 418 (2014) 311.

[21] S.K. Behera, S.Y. Oh, H.S. Park, J. Hazard. Mater. 179 (2010) 684

[22] H.Y. Li, W.W. Zhang, Z.Y. Zhang, X.R. Zhang, Sci. Total Environ. 580 (2017) 1318

[23] X.D. Zhu, Y.C. Liu, G. Luo, F. Qian, S.C. Zhang, J.M. Chen, Environ. Sci. Technol. 48 (2014) 5840.

[24] J.Y. Song, S.H. Jhung, Chem. Eng. J. 322 (2017) 366.

[25] T.H. Chen, I. Popov, W. Kaveevivitchai, O.S. Miljanic, Chem. Mater. 26 (2014) 4322.

[26] Q. Gao, J. Xu, X.H. Bu, Coordin. Chem. Rev. 378 (2019) 17.

[27] H.W. Langmi, J.W. Ren, B. North, M. Mathe, D. Bessarabov, Electrochim. Acta 128 (2014) 368.

[28] H. Bunzen, F. Kolbe, A. Kalytta-Mewes, G. Sastre, E. Brunner, D. Volkmer, J. Am. Chem. Soc. 140 (2018) 10191.

[29] L. Wang, M. Zheng, Z.G. Xie, J. Mater. Chem. B 6 (2018) 707.

[30] L. Mendecki, K.A. Mirica, ACS Appl. Mater. Inter. 10 (2018) 19248.

[31] G. Lu, J.T. Hupp, J. Am. Chem. Soc. 132 (2010) 7832.

[32] D.B. Dang, P.Y. Wu, C. He, Z. Xie, C.Y. Duan, J. Am. Chem. Soc. 132 (2010) 14321.

[33] A. Dhakshinamoorthy, Z.H. Li, H. Garcia, Chem. Soc. Rev. 47 (2018) 8134.

[34] J.P. Ma, S. Li, G.G. Wu, S.S. Wang, X.T. Guo, L.Y. Wang, X.Y. Wang, J.H. Li, L.X. Chen, J. Colloid Interf. Sci. 553 (2019) 834.

[35] Y.J. Zhao, S.J. Hou, D.H. Liu, C.L. Zhong, Ind. Eng. Chem. Res. 57 (2018) 15132

[36] Y.C. Song, N. Wang, L.Y. Yang, Y.G. Wang, D. Yu, X.K. Quyuan, Ind. Eng. Chem. Res. 58 (2019) 6394.

[37] A.Q. Liu, X. Peng, Q.B. Jin, S.K. Jain, J.M. Vicent-Luna, S. Calero, D.F. Zhao, ACS Appl. Mater. Inter. 11 (2019) 4686.

[38] P. Hu, X.P. Liang, M. Yaseen, X.D. Sun, Z.F. Tong, Z.X. Zhao, Z.X. Zhao, Chem. Eng. J. 332 (2018) 608

[39] J.H. Cavka, S. Jakobsen, U. Olsbye, N. Guillou, C. Lamberti, S. Bordiga, K.P. Lillerud, J. Am. Chem. Soc. 42 (2008) 13850.
[40] S.B. Kalidindi, S. Nayak, M.E. Briggs, S. Jansat, A.P. Katsoulidis, G.J. Miller, J.E. Warren, D. Antypov, F. Corà, B. Slater, M.R. Prestly, C. Martí-Gastaldo, M.J. Rosseinsky, Angew. Chem. Int. Edit. 54 (2015) 221.

[41] C.H. Wang, X.L. Liu, N. Keser Demir, J.P. Chen, K. Li, Chem. Soc. Rev. 45 (2016) 5107.

[42] J.L. Zhao, W. Chen, S.X. Wang, Y. Zhou, J. Ind. Eng. Chem. 83 (2020) 111.

[43] Z.J. He, Y.X. Yang, P. Bai, X.H. Guo, J. Ind. Eng. Chem. 77 (2019) 262.

[44] K.F. Wang, Y.J. Chen, R. Tian, H. Li, Y. Zhou, H.N. Duan, H.Z. Liu, ACS Appl. Mater. Inter. 10 (2018) 11333.

[45] L.N. Jin, X.S. Zhao, X.Y. Qian, M.D. Dong, J. Colloid Interf. Sci. 509 (2018) 245.

[46] Z.N. Shi, C. Xu, H. Guan, L. Li, L. Fan, Y.X. Wang, L. Liu, Q.T. Meng, R. Zhang, Colloid. Surface. A 539 (2018) 382.

[47] L.J. Huang, M. He, B.B. Chen, B. Hu, J. Mater. Chem. A 4 (2016) 5159.

[48] G.G. Wu, J.P. Ma, S. Li, J. Guan, B. Jiang, L.Y. Wang, J.H. Li, X.Y. Wang, L.X. Chen, J. Colloid Interf. Sci. 528 (2018) 360.

[49] R.Q. Zhang, Z. Wang, Z.X. Zhou, D. Li, T.F. Wang, P. Su, Y. Yang, Ind. Eng. Chem. Res. 58 (2019) 3876.

[50] Q.X. Yang, Q.Q. Zhao, S.S. Ren, Z.J. Chen, H.G. Zheng, Chem. Eng. J. 323 (2017) 74 .

[51] L.J. Huang, M. He, B.B. Chen, B. Hu, Chemosphere 199 (2018) 435.

[52] W. Wu, Q.G. He, C.Z. Jiang, Nanoscale Res. Lett. 3 (2008) 397.

[53] A.L. Morel, S.I. Nikitenko, K. Gionnet, A. Wattiaux, J. Lai-Kee-Him, C. Labrugere, B. Chevalier, G. Deleris, C. Petibois, A. Brisson, M. Simonoff, ACS Nano. 2 (2008) 847.

[54] J.H. Cavka, S. Jakobsen, U. Olsbye, N. Guillou, C. Lamberti, S. Bordiga, K.P. Lillerud, J. Am. Chem. Soc. 130 (2008) 13850.

[55] M.J. Katz, Z.J. Brown, Y.J. Colón, P.W. Siu, K.A. Scheidt, R.Q. Snurr, J.T. Hupp, O.K. Farha, Chem. Commun. 49 (2013) 9449.

[56] Y.L. Hu, Z.L. Huang, L. Jia, G.K. Li, Anal. Chem. 85 (2015) 6885.

[57] J.P. Ma, Z.D. Yao, L.W. Hou, W.H. Lu, Q.P. Yang, J.H. Li, L.X. Chen, Talanta 161 (2016) 686.

[58] Q.Y. Li, S. Jiang, S.F. Ji, M. Ammar, Q.M. Zhang, J.L. Yan, J. Solid State Chem. 223 (2015) 65.

[59] M. Kandiah, M.H. Nilsen, S. Usseglio, S. Jakobsen, U. Olsbye, M. Tilset, C. Larabi, E.A. Quadrelli, F. Bonino, K.P. Lillerud, Chem. Mater. 22 (2010) 6632.

[60] A.J. Howarth, M.J. Katz, T.C. Wang, A.E. Platero-Prats, K.W. Chapman, J.T. Hupp, O.K. Farha, J. Am. Chem. Soc. 137 (2015) 7488.

[61] C.C. Hu, Y.C. Huang, A.L. Chang, M. Nomura, J. Colloid Interf. Sci. 553 (2019) 372.

[62] D.S. Sidhaye, B.L.V. Prasad, New J. Chem. 35 (2011) 755.

[63] G. Senanayake, Hydrometallurgy 115-116 (2012) 1.

[64] P.K. Grover, R.L. Ryall, Chem. Rev. 105 (2005) 1.

[65] S. Goldberg, J. Colloid Interf. Sci. 285 (2005) 509.

[66] L. Ullah, G.Y. Zhao, N. Hedin, X.L. Ding, S.J. Zhang, X.Q. Yao, Y. Nie, Y.Q. Zhang, Chem. Eng. J. 362 (2019) 30.

[67] Y.S. Seo, N.A. Khan, S.H. Jhung, Chem. Eng. J. 270 (2015) 22.

[68] J.Y. Song, B.N. Bhadra, S.H. Jhung, Micropor. Mesopor. Mat. 243 (2017) 221.

[69] B.K. Sodipo, A.A. Aziz, J. Magn. Magn. Mater. 416 (2016) 275.

[70] M. Sarker, J.Y. Song, S.H. Jhung, Chem. Eng. J. 331 (2018) 124. 